\title{
Evaluation of 1-D Seismic Site Response Modeling of Sand using Centrifuge Experiments
}

\author{
Youssef M.A. Hashash ${ }^{1}$, Shideh Dashti ${ }^{2}$, Maria Ines Romero ${ }^{3}$, Majid Ghayoomi ${ }^{4}$, and \\ Michael Musgrove ${ }^{5}$
}

\begin{abstract}
The response of an equivalent 26 m-thick deposit of dry, medium-dense, Nevada Sand with a relative density of $60 \%$ is measured in the centrifuge under six 1-D, horizontal earthquake motions applied to the base of the centrifuge container. Several 1-D site response analysis techniques are employed to simulate the experiments, including (a) equivalent linear analyses, (b) nonlinear analyses using a multi-degree-of-freedom, lumped mass model, and (c) finite element analyses of a soil column using a pressure-dependent, multi-yield, plasticity soil model. An average $V_{s}$ profile was estimated using empirical correlations. Soil dynamic properties included published generic modulus reduction and damping curves with implied strength correction as well as recommended plasticity model parameters based on soil index properties. Computed and measured lateral displacements, accelerations, shear strains, spectral accelerations, and Arias Intensities are presented and their differences are quantified in terms of mean residuals and variance. The comparisons demonstrate that 1-D seismic site response analyses using the available strength corrected, generic, pressure-dependent modulus reduction and damping curves for medium-dense dry sand can reliably compute soil response under 1-D wave propagation using any of the three methods, with an absolute mean residual of less than 0.5 .
\end{abstract}

\footnotetext{
${ }^{1}$ Professor, University of Illinois at Urbana-Champaign, IL, USA, email: hashash@illinois.edu

${ }^{2}$ Assistant Professor, University of Colorado Boulder, CO, USA, Phone: 303.492.3118, email: shideh.dashti@ colorado.edu

${ }^{3}$ Graduate Student, University of Illinois at Urbana-Champaign, IL, USA, email: romeroa2@illinois.edu

${ }^{4}$ Assistant Professor, University of New Hampshire, NH, USA, email: majid.ghayoomi@unh.edu

${ }^{5}$ Graduate Student, University of Illinois at Urbana-Champaign, IL, USA, email: mmusgro2@illinois.edu
} 


\section{INTRODUCTION}

Site response analyses are an important first step in the seismic evaluation of many geotechnical structures and soil-structure interaction problems. These analyses are used to estimate ground surface motions for the development of design response spectra, dynamic stresses, strains, and displacements within the soil profile and liquefaction hazard analyses. Seismic ground response analyses are often performed in practice using equivalent linear procedures; nonlinear analyses are used less frequently due to concerns about parameter selection and code usage protocols (Matasovic and Hashash 2012).

Recent work from Afacan et al. (2014) on centrifuge modeling of site response in soft clays over a wide range of strains that included nearly linear to strongly nonlinear soil behavior concluded that centrifuge tests using a hinged-plate container are valuable to understand 1-D seismic ground response and to validate nonlinear site response from empirical and numerical models. They did not present a comparison with numerical simulations in the paper, but according to the results presented, the Darendeli (2001) functional form appeared to provide a reasonable characterization of the observed modulus-reduction behavior in the centrifuge models. Damping values computed from the centrifuge measurements exhibited significant scatter and tended to be greater than the published values. Amplification of response spectral accelerations observed were compared with those predicted using NGA ground-motion prediction equations (GMPE) to evaluate the nonlinear terms in the GMPEs; good agreement was found for large values of horizontal peak ground acceleration.

This paper evaluates the performance of several 1-D site response analysis techniques using centrifuge testing on sand. It is acknowledged that centrifuge test results are also a model of real soil behavior with a range of limitations and simplifications, such as boundary effects, 
scaling laws, and a simplistic soil profile and loading conditions. Despite its limitations, however, it is a useful tool to gain insight into soil behavior under well-controlled conditions. In this paper, different numerical simulation techniques are evaluated in view of centrifuge test results, bearing in mind the uncertainties associated with centrifuge modeling.

The soil profile considered for the analyses is a 26 m-thick layer of dry, Nevada Sand at approximately $60 \%$ relative density. The free-field behavior of the soil column is studied under a sequence of six 1-D, horizontal earthquake base motions. Class $\mathrm{C}$ and $\mathrm{C} 1$ predictions are performed and compared with centrifuge test results in terms of acceleration, lateral displacement, shear strain profiles, spectral accelerations, and Arias Intensities. The prediction classification used in this paper is that described by Lambe (1973). A Class A blind prediction is performed before the event (or experiment) being predicted has occurred. A Class B prediction is one made during the event. A Class $\mathrm{C}$ prediction is one made after the event, but without knowing the results at the time the prediction is made. A Class $\mathrm{C} 1$ prediction is one made after the event and the results are known at the time of prediction. Class $\mathrm{C}$ predictions are conducted using DEEPSOIL v5.0 (Hashash et al. 2011) and OpenSees v.2.3.2 (Mazzoni et al. 2006) with selected soil constitutive models. An average shear wave velocity $\left(\mathrm{V}_{\mathrm{s}}\right)$ profile employed in all analyses was estimated using the Bardet et al. (1993) and Seed and Idriss (1970) empirical correlations. The soil parameters are selected based on the soil type as well as measured and estimated sand properties. Class $\mathrm{C} 1$ predictions are made using OpenSees to better capture the experimentally measured free-field soil response in the finite element model.

\section{EXPERIMENTAL PROGRAM}

One centrifuge experiment, subjected to multiple 1-D earthquake motions, was performed to simulate 1-D site response in a 26 m-thick layer of dry Nevada Sand with a relative density 
$\left(D_{r}\right)$ of approximately $60 \%$. The experiment was conducted at the University of Colorado Boulder centrifuge facility. The soil specimen was spun to a centrifugal acceleration of $77 \mathrm{~g}$. All dimensions and units presented in this paper are in prototype scale, unless stated otherwise.

\section{Soil Properties}

Nevada Sand (No. 120) is a fine, poorly graded, and angular sand with a gradation curve shown in Figure 1. The minimum and maximum dry densities of the batch of sand tested were measured as 14.00 and $16.39 \mathrm{kN} / \mathrm{m}^{3}$, as summarized in Table 1 along with other measured material properties.

\section{Model Test Configuration, Preparation, and Instrumentation}

The soil specimen was constructed in a flexible-shear-beam (FSB) container with inside dimensions of $30.48 \mathrm{~cm}$ in width, $69.85 \mathrm{~cm}$ in length, and $33.8 \mathrm{~cm}$ in height in model scale (Ghayoomi et al. 2013). A 388 mm-thick (model scale) layer of \#120 Nevada Sand was drypluviated into the container using a barrel hopper at a constant drop-height to achieve a $D_{\mathrm{r}}$ of approximately $60 \%$. The thickness of the soil layer was selected based on the height of model midrise and highrise buildings that were to be placed on the soil in subsequent tests and the available overhead space in centrifuge.

The instrumentation layout was designed to measure lateral displacements and horizontal accelerations in soil at different depths, in addition to soil settlement (Figure 2). A vertical array of horizontal linear variable displacement transducers (LVDTs) was mounted on the container frames, recording the horizontal movement of each frame with respect to a reference external rack that was connected to the centrifuge platform. The vertical LVDTs (LVDTs 7 and 8) were mounted to measure settlements at the soil surface. There were three arrays of accelerometers, 
labeled as Central (Acc2, 4, 6, 8, 10 and 11), Side (Acc12, 13, 14 and 15), and Box (Acc1, 3, 5, 7, 9) Arrays. The Central and Side Arrays refer to accelerometers placed inside the soil in the center and near the boundary of the container, respectively. The Box Array refers to accelerometers mounted externally on each container frame.

The soil specimen was first spun to the target centrifugal acceleration of $77 \mathrm{~g}$. Then a series of earthquake motions were applied to the base of the model container in the order presented in Table 2. The 1-D, hydraulic, servo-controlled shake table mounted on the centrifuge platform was used in this experiment with a controllable frequency range between approximately 10 to $300 \mathrm{~Hz}$ in model scale.

\section{Input Motions}

A suite of six earthquake motions recorded on rock or stiff soil was selected as the base motion in centrifuge to cover a wide range of amplitudes (e.g., Arias Intensities, AI, between 1.98 and $9.16 \mathrm{~m} / \mathrm{s}$, and peak ground accelerations, PGA, between 0.33 and $0.76 \mathrm{~g}$ ), frequency contents (e.g., predominant periods, $\mathrm{T}_{\mathrm{p}}$, between 0.28 and $0.64 \mathrm{sec}$ ), and durations (e.g., significant duration between 5 and $95 \%$ of the AI, $\mathrm{D}_{5-95}$, between 11.34 and $28.76 \mathrm{sec}$ ). The properties of the suite of achieved base motions measured in centrifuge are summarized in Table 2. The acceleration time histories and Arias Intensity time histories of the motions recorded at the base of the container are shown in Figure 3. The motion recorded at the base of the container during centrifuge testing was used as input to the site response analyses (average of Acc1 and 16 used as a within rock motion). 


\section{Instrumentation}

The strain profile during each motion was obtained from both LVDT and accelerometer recordings using the procedure outlined by Zeghal et al. (1995). The lateral displacement profile was obtained directly from the horizontal LVDT measurements on the container frames. The LVDT recordings indicated a small lateral displacement offset on each frame at the end of shaking. The maximum value of this permanent displacement offset was recorded on the top frame (LVDT 6), as summarized in Table 3, varying from 0.003 to $0.032 \mathrm{~m}$ in prototype scale. Although the offset was quite small in model scale (ranging from 0.04 to $0.4 \mathrm{~mm}$,), it could influence the estimated strain profiles. The PGA profile was obtained directly from the three arrays of horizontal accelerometers shown in Figure 2. Acc.12 malfunctioned and its readings are not presented. The acceleration time histories were passed through a fourth-order, casual, bandpass, Butterworth filter with corner frequencies of 0.1 and $25 \mathrm{~Hz}$ (in prototype scale) to eliminate noise, and then integrated twice to obtain displacement time histories. This choice of filter was conservative, as these corner frequencies fell well beyond the shake table's capability.

Soil surface settlement was measured at two locations across the container by vertical LVDTs 7 and 8 (shown in Figure 2). The change in soil relative density after each motion was estimated using these settlement recordings and the corresponding 1-D volumetric strains. The change in soil relative density ranged from approximately 0.1 to $4 \%$ during different motions. As expected, more soil densification was observed during stronger motions (e.g., greater PGA). However, because the observed change in soil density was small in view of the uncertainties involved in the estimated soil properties experimentally, a constant soil relative density of $60 \%$ was maintained in the subsequent Class $\mathrm{C}$ numerical predictions during all motions. 


\section{SITE RESPONSE ANALYSIS METHODS}

In a linear site response analysis, the maximum soil stiffness and a constant damping ratio are considered throughout the entire time history. In an equivalent linear, frequency domain site response analysis, an equivalent soil stiffness and damping value are considered for each layer for the entire duration of a seismic event. This can lead to an over or under estimation of the damping and soil stiffness, depending on the strain level the soil response is being analyzed. In a nonlinear, time domain analysis, the variation of soil shear modulus $(\mathrm{G})$ and damping ratio $(\xi)$ is considered in the material during shaking. One dimensional (1-D), linear, equivalent-linear, and nonlinear site response analyses were conducted for the measured centrifuge base motions in prototype scale using DEEPSOIL v5.0 and OpenSees v.2.3.2.

\section{Nonlinear Site Response Analyses in DEEPSOIL}

In nonlinear site response analyses in DEEPSOIL, the soil column is discretized as a multi-degree-of-freedom (MDOF), lumped mass model, whereby each individual layer is represented by a corresponding mass, nonlinear spring, and a dashpot representing viscous damping. Lumping half of the mass of each of two consecutive layers at their common boundary forms the mass matrix, and the stiffness matrix is updated at each time increment to incorporate soil nonlinearity (Phillips and Hashash 2009). In this work, the soil profile was subdivided into sixteen, $1 \mathrm{~m}$-thick layers from the surface to $16 \mathrm{~m}$ depth and five, $2 \mathrm{~m}$-thick layers from $16 \mathrm{~m}$ to 26 m depth.

The soil backbone response is obtained from a constitutive hyperbolic model that describes the cyclic behavior of the soil. The hysteretic behavior is modeled using the four extended unload-reload Masing rules with the modification proposed by Phillips and Hashash 
(2009). The hysteretic damping at small strains is nearly zero. In DEEPSOIL, frequencyindependent viscous damping formulation described by Phillips and Hashash (2009) is employed to represent damping at very small strains. For hysteretic damping, a reduction factor that modifies the Masing unloading-reloading rules (MRDF procedure) to provide a better agreement with empirical damping curves is used as described by Phillips and Hashash (2009).

\section{Nonlinear Site Response Analyses in OpenSees}

Nonlinear finite element analyses were conducted using the single-phase formulation of the pressure-dependent, multiyield (PDMY) material constitutive model (Elgamal 2002; Parra 1996; Yang 2000) implemented in OpenSees (Mazzoni et al. 2006). The model is based on multiyield surface plasticity, where conical yield surfaces with different tangent moduli are used to represent shear stress-strain nonlinearity and confinement dependence of shear strength. Small strain damping is represented by Rayleigh damping with two controlling frequencies.

The finite element model was defined using 8-node isoparametric BbarBrick elements, which are mixed volume-pressure brick elements using a trilinear isoparametric formulation (Mazzoni et al. 2006). Previous work has shown that 1-D free-field response can be properly modeled assuming a shear beam behavior (Phillips et al. 2012). Hence, in this paper, a shear beam approach was used with 21 elements to define the $26 \mathrm{~m}$ soil column. From depth 0 to $16 \mathrm{~m}$, soil elements of $1 \mathrm{~m}$ thickness were used, and from depth 16 to $26 \mathrm{~m}$, soil elements of $2 \mathrm{~m}$ thickness were used.

\section{MODEL INPUT PARAMETERS}

The soil properties needed to perform the numerical analyses are: dry unit weight, void ratio (e), relative density $\left(\mathrm{D}_{\mathrm{r}}\right)$, friction angle $\left(\phi^{\prime}\right)$, coefficient of at rest lateral earth pressure $\left(\mathrm{K}_{\mathrm{o}}\right)$, 
shear wave velocity profile $\left(\mathrm{V}_{\mathrm{s}}\right)$, modulus reduction curves, damping curves, and small strain damping ratio. Table 1 summarizes the soil properties that were measured or estimated to be used in the numerical analyses, several of which are discussed in this section. The friction angle $\left(\phi^{\prime}\right)$ was estimated from the relationship between $\left(\mathrm{N}_{1}\right)_{60}$ and friction angle for fine grained sands presented by Terzaghi et al. (1996). $\left(\mathrm{N}_{1}\right)_{60}$ was estimated from the soil's relative density using the empirical correlation proposed by Terzaghi and Peck (1948). The coefficient of at rest lateral earth pressure $\left(\mathrm{K}_{\mathrm{o}}\right)$ was estimated using Jaky's equation for normally consolidated sands (Mesri and Hayat 1993).

$$
K_{o}=1-\sin \left(\phi^{\prime}\right)
$$

\section{Shear Wave Velocity Profile $\left(\mathbf{V}_{\mathrm{s}}\right)$}

The shear wave velocity profile was estimated as the average of the empirical procedures proposed by Seed and Idriss (1970) and Bardet et al. (1993), as shown in Equations (2) and (4) and in Figure 4.

Seed and Idriss (1970): $\quad G_{\max }=1000 K_{2, \max }\left(\sigma_{m}^{\prime}\right)^{0.5}$

where $G_{\max }$ is the maximum shear modulus of sand at small strains, $K_{2, \text { max }}$ is determined from the soil's void ratio or relative density based on Table 6-4 of Kramer (1996), and $\sigma_{m}^{\prime}$ is the mean principal effective stress in units of $\mathrm{lb} / \mathrm{ft}^{2}$ :

$$
\sigma_{m}^{\prime}=\frac{2 \sigma_{h}^{\prime}+\sigma_{v}^{\prime}}{3}
$$

Bardet et al. (1993) measured the elastic shear modulus of Nevada Sand through resonant column tests at small strains $\left(<10^{-6} \%\right)$ for relative densities of $40 \%$ and $60 \%$. The measured 
value of small strain shear modulus $\left(G_{\max }\right)$ was a function of the applied mean pressure, which was expressed as a power law:

$$
G_{\max }=G_{o} p^{n}=A \frac{(a-e)^{2}}{1+e} p^{n}
$$

where $e$ is soil's void ratio, $\mathrm{p}$ is mean pressure expressed in $\mathrm{kPa}$, and the constants $\mathrm{n}=0.5$, $\mathrm{A}=8.811$, and $\mathrm{a}=1.935$ were determined for Nevada Sand. The soil's shear wave velocity $\left(V_{s}\right)$ was then estimated using Equation (5):

$$
V_{s}=\sqrt{\frac{G_{\max }}{\rho}}
$$

where $\rho$ is soil mass density. According to NEHRP (2004) and the $\mathrm{V}_{\text {s }}$ profile considered, the soil profile was classified as site class D: stiff soil with $180(\mathrm{~m} / \mathrm{s}) \leq \bar{V}_{s 30} \leq 360(\mathrm{~m} / \mathrm{s})$. The minimum wavelength $\left(\lambda_{\min }\right)$ that can travel through the soil column may be estimated as $4 . h$, where $h$ is the element size used in the analyses. The maximum frequency $\left(f_{\max }\right)$ of the propagating wave may then be estimated as $V_{\mathrm{s}} / \lambda_{\min }$. In the site response analyses presented in this paper, based on the choice of element size and estimated shear wave velocities at different depths, $\mathrm{f}_{\max }$ was greater than $25 \mathrm{~Hz}$, which was in turn much greater than the maximum frequency achieved by the centrifuge shake table in prototype scale.

\section{Modulus Reduction and Damping Curves in DEEPSOIL}

The parameters required as input to define Darendeli's modulus reduction and damping curves (Darendeli 2001) are effective vertical stress $\left(\sigma_{v}{ }^{\prime}\right)$, the coefficient of at rest lateral earth pressure $\left(K_{o}\right)$, the plasticity index $(P I)$, the overconsolidation ratio $(O C R)$, the loading frequency (Freq.), and the number of loading cycles $(N)$, as summarized in Table 4 . The implied friction 
angle profile at large strains using those modulus reduction and damping curves was significantly less than the soil's target friction angle, as shown in Figure 5. The curves were modified following the procedure described by Hashash et al. (2010), as illustrated in Figure 6 for the top layer. The procedure consisted of five steps: 1) fitting the target curve for the soil using an MRDF model, in this case Darendeli's MRDF; 2) computing the implied soil shear strength as the maximum shear stress value for all the points on the modulus reduction curve; 3 ) comparing the implied shear strength with the target shear strength; 4) if the implied strength is lower than the target shear strength for shear strains larger than $0.1 \%$, manually increasing the modulus reduction points, such that the implied shear strength is larger than the target value, and 5) fitting the modified modulus reduction using the MRDF procedure. A subset of the modulus reduction curves, damping curves, and shear stress-strain relationships used in the analyses is shown in Figure 7.

\section{PDMY Model Parameters in OPENSEES}

The parameters used to define the model are mass density, reference shear modulus $\left(G_{r}\right)$, reference mean confining pressure $\left(p_{r}^{\prime}\right)$, Poisson's ratio, reference bulk modulus $\left(\mathrm{B}_{\mathrm{r}}\right)$, confinement dependence coefficient $(\mathrm{d})$, friction angle $\left(\phi^{\prime}\right)$, peak shear strain $\left(\gamma_{\max }\right)$, number of yield surfaces, phase transformation angle, initial void ratio, contraction and dilation parameters, and liquefaction induced strain constants, which are presented in Table 5.

The reference shear modulus $\left(G_{r}\right)$ at the reference mean confining pressure $\left(p_{r}^{\prime}\right)$ of $80 \mathrm{kPa}$ was used to obtain the shear wave velocity profile $\left(\mathrm{V}_{\mathrm{s}}\right)$ described earlier (Figure 4). The Poisson's ratio was selected to result in the required friction angle for a normally consolidated sand, and the reference bulk modulus $\left(B_{r}\right)$ was calculated using the elastic relation between low 
strain shear modulus and Poisson's ratio, similar to the approach used by Al Atik and Sitar (2010).

The contraction and dilation parameters were those recommended in the OpenSees manual (Yang 2010) for medium and medium dense sands. The confinement dependence coefficient, peak shear strain, number of yield surfaces, and phase transformation angle used were those recommended in the OpenSees manual (Yang 2010) for medium dense sand. A subset of the modulus reduction curves and shear stress-strain relationships used in the analyses is shown in Figure $7 \mathrm{a}$ and $7 \mathrm{c}$.

\section{Small Strain Damping}

In the DEEPSOIL analyses, the small strain damping profile was obtained from Darendeli's damping curves. For the set of properties previously defined, it varied from $1.85 \%$ in the top layer to $0.55 \%$ in the bottom layer. In the nonlinear analyses, the frequency-independent damping formulation was used to properly account for energy dissipation at small strains.

In OpenSees, small strain damping can only be introduced by the Rayleigh and Lindsay formulation, where the damping matrix $[\mathrm{C}]$ is proportional to the mass $[\mathrm{M}]$ and rigidity $[\mathrm{K}]$ matrices (Rayleigh and Lindsay 1945):

$$
[C]=a_{o}[M]+a_{1}[K]
$$

where $\mathrm{a}_{0}$ and $\mathrm{a}_{1}$ are scalar values selected to obtain given damping values for two control frequencies.

Park and Hashash (2004) described the application of the full Rayleigh formulation in 1D site response analyses. For soil profiles with a constant damping ratio, scalar values $a_{o}$ and $a_{1}$ can be calculated using two significant natural modes $\mathrm{i}$ and $\mathrm{j}$ as follows: 


$$
\left[\begin{array}{l}
\xi_{i} \\
\xi_{j}
\end{array}\right]=\frac{1}{2}\left[\begin{array}{cc}
\frac{1}{2 \pi f_{i}} & 2 \pi f_{i} \\
\frac{1}{2 \pi f_{j}} & 2 \pi f_{j}
\end{array}\right]\left\{\begin{array}{l}
a_{o} \\
a_{1}
\end{array}\right\}
$$

where $\xi_{i}$ and $\xi_{j}$ are the damping ratios for the frequencies $f_{i}$ and $f_{j}$ of the system. In this analysis, the damping ratio used was $3 \%$, and the controlling frequencies were the small-strain fundamental frequency of the soil column, $f_{i}=\overline{V S} /(4 \mathrm{H})=2.24(\mathrm{~Hz})$, and 5 times the fundamental frequency, $f_{j}=11.2(\mathrm{~Hz})$. The damping ratio and the control frequencies were selected based on the calibration results shown by Phillips et al. (2012), resulting in $a_{o}=0.7037$ and $a_{1}=0.0007$.

\section{SITE RESPONSE ANALYSIS RESULTS FOR SELECTED MOTIONS}

The general soil profile response was evaluated by means of maximum and minimum displacement profiles, PGA profiles, maximum shear strain profile, Arias Intensity time histories, and the surface 5\%-damped acceleration response spectra for the six motions selected.

\section{Linear Visco-Elastic Analyses}

Linear visco-elastic analyses were first performed using the MDOF lumped mass and finite element models to verify that the two analysis procedures yield similar results for a viscous-elastic soil model. The finite element (OpenSees) and the MDOF lumped mass (DEEPSOIL) analyses yielded similar results in the linear elastic range for the six input motions in terms of maximum and minimum displacement profiles, maximum shear strain profiles, and surface response spectra. The PGA profile showed some variations in the middle of the soil column during the KobeTAK, NorthridgeWPI, and LandersLCN motions. 


\section{Class C Predictions}

Class C, site response analyses included: a) MDOF, lumped mass analyses with equivalent linear and nonlinear soil properties, and b) finite element analysis with the PDMY soil model. A comparison of the maximum lateral displacement profiles, PGA profiles, maximum shear strain profiles, 5\%-damped surface acceleration response spectra, and surface Arias Intensity time histories was generated between Class $\mathrm{C}$ numerical predictions and centrifuge measurements for all the input motions. Figure 8 and Figure 9 present the comparisons during two representative motions (e.g., LomaSCZ and KobeTAK). These motions are presented because they had the lowest and highest PGA values and resulted in the minimum and maximum levels of shear strain induced in the soil column.

During the LomaSCZ motion, the computed maximum and minimum displacement profiles from all methods were close to the centrifuge measurements (Figure 8a). As shown in Figure $8 \mathrm{~b}$, the OpenSees analyses overestimated the PGA values. The measured PGA values obtained from the central accelerometer array were closer to those computed from the DEEPSOIL nonlinear analyses. When comparing the maximum strain profiles, all numerical predictions fell in between the experimental strains obtained from LVDTs and accelerometers below depth of $9 \mathrm{~m}$. However, above $9 \mathrm{~m}$, the closest prediction was obtained from the finite element analyses (Figure 8c). Figure 8d shows that the surface acceleration response spectrum obtained from the DEEPSOIL nonlinear analysis compared best with that measured in centrifuge. DEEPSOIL equivalent linear and OpenSees nonlinear predictions showed larger acceleration response spectra in periods $(\mathrm{T})$ greater than about $0.2 \mathrm{sec}$. Figure 8e shows that the OpenSees nonlinear analysis overestimated the Arias Intensity at the surface by a factor of about two. The DEEPSOIL nonlinear and equivalent linear analyses both provided surface Arias 
Intensity time histories that were closer to those obtained experimentally. Nonlinear DEEPSOIL analyses provided the best predictions of Arias Intensity during this event.

Figure 9 compares the Class $\mathrm{C}$ predictions with centrifuge measurements during the KobeTAK motion. The positive maximum lateral displacement profiles (Figure 9a) obtained from the DEEPSOIL nonlinear and equivalent linear analyses were closer to the centrifuge measurements, while the finite element results did not agree well. The three analysis procedures overestimated the centrifuge measurements in terms of PGA (Figure 9b), with the DEEPSOIL nonlinear method providing the closest match. The maximum strain profiles obtained from DEEPSOIL equivalent linear and nonlinear analyses compared well with those measured at depths below $10 \mathrm{~m}$ (Figure 9c). Above $10 \mathrm{~m}$, however, both predictions overestimated the maximum strains by a factor of about 4 to 6 . The finite element model underestimated the shear strain profile. For the surface acceleration response spectra shown in Figure 9d, the DEEPSOIL nonlinear analysis provided the closest match to the centrifuge results. The finite element analysis overestimated the response at periods between 0.2 and $1 \mathrm{sec}$; the DEEPSOIL equivalent linear analysis overestimated the response in the period range of 0.2 and $3 \mathrm{sec}$. The computed Arias Intensity values (Figure 9e) were overestimated by a factor of 3 and 2 when using the DEEPSOIL equivalent linear and finite element analyses, respectively. The surface Arias Intensity time history predicted from the DEEPSOIL nonlinear analysis was at most $20 \%$ greater than the measured time history. A similar trend was observed during the other motions. The quantification of error between different analysis procedures and centrifuge measurements as well as possible reasons for the differences will be discussed in a later section for all motions. 


\section{Class C1 Predictions}

The soil model parameters used in the nonlinear finite element analyses were updated or recalibrated based on the observations from Class $\mathrm{C}$ predictions. In the recalibration process, the shear wave velocity profile estimated in the Class C simulations (Figure 4) was maintained. The strength-corrected Darendeli's modulus reduction curves used in the DEEPSOIL nonlinear analyses yielded the best overall comparisons with centrifuge measurements. Therefore the same curves were used as target to recalibrate the modulus reduction curves in the OpenSees Class C1 simulations, whereas Class C OpenSees simulations used automatically generated values of shear modulus. The modulus reduction curves in Class $\mathrm{C} 1$ simulations were manually incorporated using the procedure described in the OpenSees manual (Mazzoni et al. 2006; Yang 2010).

The last pair of strain and shear modulus in the backbone curve must be adjusted so as to reach the appropriate friction angle, because the friction angle specified by the user is ignored when the modulus reduction curves are added manually (Mazzoni et al. 2006; Yang 2010). The friction angle was calculated using Equation ((8):

$$
\sin \phi=\frac{3 \sqrt{3} \sigma_{m} / p_{r}^{\prime}}{6+\sqrt{3} \sigma_{m} / p_{r}^{\prime}}
$$

where $\sigma_{m}$ is the product of the last modulus and strain pair in the modulus reduction curves and $p_{r}^{\prime}$ as defined in Table 5 (Mazzoni et al. 2006; Yang 2010).

As shown in Figure 5, the friction angle estimated before modifying the last pair of strain and modulus was between 40 and 50 degrees, which was unrealistic for this type of soil. After the modification, soil friction angle was reduced to 33 degrees. Figure 7a compares the modulus reduction curves that were manually entered into OpenSees (i.e., OpenSees Class C1 curves) to 
the ones used in DEEPSOIL and OpenSees Class C simulations at the surface and depths of 6.5 $\mathrm{m}, 13.5 \mathrm{~m}, 19 \mathrm{~m}$, and $25 \mathrm{~m}$. The modulus reduction curves used in OpenSees Class $\mathrm{C} 1$ analyses agreed with those of DEEPSOIL Class C analyses.

Some of the shear stress-strain curves obtained from the Class $\mathrm{C}$ and $\mathrm{C} 1$ analyses are compared in Figure 7c. It should be noted that the shear stress vs. shear strain results obtained from OpenSees considers a 3-D failure criteria, which is not considered in the DEEPSOIL analyses.

The OpenSees Class $\mathrm{C}$ and $\mathrm{C} 1$ predictions are compared with the centrifuge measurements during the LomaSCZ and KobeTAK motions in Figure 10 and Figure 11, respectively. The Arias Intensity time histories (Figure 10e and Figure 11e) and the acceleration response spectra (Figure 10d and Figure 11d) obtained from the OpenSees Class C1 analyses improved noticeably compared to the Class $\mathrm{C}$ predictions. The maximum and minimum displacement profiles (Figure 10a and Figure 11a) and the shear strain profiles (Figure 10c and Figure 11c) also improved. The PGA profile during the LomaSCZ motion (Figure 10b) improved in the upper $10 \mathrm{~m}$ and maintained similar values for the lower $16 \mathrm{~m}$. The PGA profile during the KobeTAK motion (Figure 11b), however, did not show an improvement.

\section{EVALUATION OF ANALYSIS RESULTS FOR ALL MOTIONS}

To better evaluate the difference between numerical predictions and centrifuge measurements during six different base motions, residuals were calculated. For each analysis type and for each input motion, a dimensionless residual was calculated using Equation (9):

$$
\text { Residual } X=\log \left(\frac{X_{\text {measured }}}{X_{\text {predicted }}}\right)
$$




\section{Residual $X>0$ : Underestimation \\ Residual $X<0$ : Overestimation}

where $\mathrm{X}$ refers to a given response parameter of interest: the positive and negative peak lateral displacement, absolute PGA, absolute maximum strain, surface acceleration response spectra, and Arias Intensity time histories. Figure 12 shows the mean residual computed for each analysis type and each response parameter as the average of the residuals obtained during six different motions. Figure 13 summarizes the range of mean residuals and variances obtained for each analysis type and response parameter.

In general, there was good agreement between Class C DEEPSOIL nonlinear predictions and centrifuge measurements, especially in terms of the maximum displacement and PGA profiles (peak absolute residual of 0.153). The variance in different response parameters obtained with this method was also generally lower than other analysis procedures (e.g., peak variance of about 0.16 ). The response obtained from Class $\mathrm{C}$ OpenSees nonlinear analyses appeared to be too stiff, overestimating the surface response spectra and Arias Intensity time histories, while underestimating the shear strain profiles (Figure 13). Therefore, the modulus reduction curves were modified in the subsequent Class $\mathrm{C} 1$ analyses to better assess 1-D site response. Class $\mathrm{C} 1$ OpenSees predictions gave estimates that better agreed with centrifuge measurements during all six motions compared to OpenSees Class C predictions. The variance in predictions, however, did not significantly improve in Class $\mathrm{C} 1$ OpenSees analyses. The following subsections present a comparison and quantification of the results for each method of analysis and each parameter. 


\section{Surface Response Spectra}

In general, the analyses overestimated the response spectra in periods ranging from 0.3 to $1 \mathrm{sec}$ (Figure 12). The response spectra estimated at the surface from the DEEPSOIL nonlinear analyses were the closest to the centrifuge measurements, with mean residuals ranging from 0.049 to -0.249 , as can be seen in Figure 13 . The DEEPSOIL equivalent linear analyses mostly overestimated the response spectra, with residuals ranging from 0.023 to -0.5 .

Class $\mathrm{C} 1$ surface response spectra predictions obtained from OpenSees were close to Class C DEEPSOIL nonlinear analyses in periods ranging from 0.2 to $1 \mathrm{sec}$, with an absolute maximum residual of 0.305 . The response did not change significantly compared to Class $\mathrm{C}$ predictions in periods less than $0.08 \mathrm{sec}$ and greater than $0.7 \mathrm{sec}$, but the residual range decreased significantly as shown in Figure 13.

\section{PGA Profiles}

Figure $12 \mathrm{~b}$ shows the residuals between the predicted absolute PGA profiles and the experimental measurements. These PGA values were consistently overestimated in all the analyses, as shown in Figure 13. The closest prediction was obtained from the DEEPSOIL analyses (residuals ranging from -0.009 to -0.153 for the nonlinear analysis, and from -0.002 to 0.179 for the equivalent linear analysis). Comparing the results from the Class $\mathrm{C}$ and Class $\mathrm{C} 1$ OpenSees analyses, the only parameter that did not improve was the PGA prediction for depths below $7 \mathrm{~m}$. 


\section{Surface Arias Intensity Time Histories}

All analysis methods explored in this study overestimated the Arias Intensity time histories at the surface compared to the centrifuge measurements (Figure 13). DEEPSOIL nonlinear predictions were the closest to experimental values, with mean residuals ranging from 0.035 to -0.14 . DEEPSOIL equivalent linear and OpenSees Class $\mathrm{C}$ predictions similarly overestimated the Arias Intensities, with mean residuals ranging from -0.109 to -0.515 . Class $\mathrm{C} 1$ OpenSees predictions improved significantly, getting closer to the values obtained by the Class C DEEPSOIL nonlinear predictions with a maximum residual of 0.23 .

\section{Maximum Shear Strain Profiles}

The mean residuals between the maximum absolute shear strain profiles obtained from DEEPSOIL nonlinear and equivalent linear analyses are shown to be around zero in Figure 12. DEEPSOIL nonlinear analyses had a mean residual ranging from -0.007 to -0.368 (Figure 13).

The maximum shear strain profile obtained from Class C1 OpenSees analyses showed improvement with respect to Class $\mathrm{C}$ OpenSees predictions, with a mean residual ranging from 0.112 to 0.249 compared to the mean residual ranging from 0.23 to 0.366 calculated based on Class C predictions. However, both predictions underestimated the response throughout the profile (Figure 13).

\section{Lateral Displacement Profiles}

Figure 12a shows the mean residuals for the maximum and minimum lateral displacement profiles. As shown in Figure 13, the smallest residuals were obtained from the DEEPSOIL nonlinear analyses, ranging from -0.004 to 0.112 in the positive direction of displacement. The 
DEEPSOIL equivalent linear analyses also showed small residuals (-0.024 to 0.106$)$ in the positive direction. Both nonlinear and equivalent linear DEEPSOIL analysis results had residuals that were centered around zero, showing overestimation and underestimation of the response.

The lateral displacements obtained from Class C1 OpenSees nonlinear analyses agreed well with those of Class C DEEPSOIL nonlinear analyses and the centrifuge measurements in the positive direction (residual: 0.027 to 0.148 ), but not in the negative direction (residual: -0.073 to 0.285$)$. Generally, the displacements were underestimated across the soil column.

\section{SUMMARY AND CONCLUSIONS}

The response of a 26 m-thick deposit of dry, medium-dense, Nevada Sand with a relative density of approximately $60 \%$ was studied in centrifuge under six, 1-D, horizontal earthquake motions applied to the base of the container. The measured response was compared with predictions using different numerical modeling techniques and analysis types, including linear visco-elastic, equivalent linear, and nonlinear analyses in DEEPSOIL and OpenSees. The global response of the soil profile was evaluated using mean residuals of the lateral displacement profiles, PGA profiles, maximum strain profiles, 5\%-damped surface acceleration response spectra, and Arias Intensity time histories during different motions for each analysis type. The strength-corrected Darendeli's modulus reduction curves used in the Class C DEEPSOIL nonlinear analyses provided the best overall comparisons with centrifuge measurements, particularly for PGA and maximum lateral displacements with a peak absolute residual of 0.153. The mean residuals for all parameters obtained from these analyses were narrower (i.e., smaller variance) and closer to zero compared to the other analysis methods.

DEEPSOIL equivalent linear analyses provided reasonable estimates of the response in terms of displacement and absolute PGA profiles when the base motion had a PGA less than 0.5 
$\mathrm{g}$, but not in terms of acceleration response spectra and Arias Intensity time histories. The primary limitation of the equivalent linear method was its use of a constant soil shear modulus and damping throughout the entire time history, underestimating the shear modulus and overestimating the damping at small strains and the opposite at large strains. During some of the motions used in this study, large shear strains were predicted, questioning the validity of using equivalent linear simulations in those cases.

The response obtained from Class C OpenSees nonlinear analyses was too stiff, overestimating the surface response spectra and Arias Intensity time histories, while underestimating the shear strain profiles. The incorporation of the same modulus reduction curves used in DeepSoil in the Class C1 OpenSees nonlinear analyses significantly improved the predictions (peak absolute mean residual of 0.305 compared to 0.52 ). One of the limitations of this method was its incorporation of small-strain damping using the Rayleigh damping formulation. Additionally, this method uses the unmodified Masing rules that, unlike the MRDF Darendeli's model curves, overestimate large strain damping. However, the advantage of the finite element model is its capacity to further incorporate 2-D and 3-D complexities and soilstructure interaction, which was important in this study.

A proper selection of dynamic soil properties (e.g., $\mathrm{V}_{\mathrm{s}}$ profile as well as modulus reduction and damping curves) is necessary to reliably predict 1-D site response. In particular, incorporating the strength-corrected Darendeli's generalized modulus reduction and damping curves in both DEEPSOIL and OpenSees is shown to be important for a more reliable prediction of 1-D site response in terms of PGA, spectral acceleration, Arias Intensity, maximum lateral displacement, and shear strain profiles.

\section{ACKNOWLEDGMENTS}

Page: 22 of 45 
This material is based upon work supported by the National Science Foundation under Grant no. 1134968. Any opinions, findings, and conclusions or recommendations expressed in this material are those of the authors and do not necessarily reflect the views of the National Science Foundation.

Page: 23 of 45 


\section{REFERENCES}

Afacan, K. B., Brandenberg, S. J., \& P.Stewart, J. (2014). Centrifuge Modeling Studied of Site Response in Soft Clay over Wide Strain Range. Journal of Geotechnical \& Geoenvironmental Engineering, 140(2). doi: 10.1061/(ASCE)GT.1943-5606.0001014

Al Atik, L., \& Sitar, N. (2010). Seismic Earth Pressures on Cantilever Retaining Structures. Journal of Geotechnical and Geoenvironmental Engineering, 136(10), 1324-1333. doi: 10.1061/(ASCE)GT.1943-5606.0000351

Bardet, J. P., Huang, Q., \& Chi, S. W. (1993, 17-20 October 1993). Numerical prediction Model No 1. Paper presented at the Proceedings of the International Conference on the Verification of Numerical Procedures for the Analysis of Soil Liquefaction Problems, U.C. Davis, USA.

Building Seismic Safety Council (BSSC). (2004). NEHRP recommended provisions and commentary for seismic regulations for new buildings and other structures (FEMA 450), 2003 edition. Washington, D.C.: National Institute of Building Sciences.

Darendeli, M. B. (2001). Development of a new family of normalized modulus reduction and material damping curves. Ph. D., University of Texas at Austin, Austin. Retrieved from C:IYH_library $\backslash D \backslash D a r e n d e l i \_2001 . p d f$

Elgamal, A., Yang, Z. and Parra, E. (2002). Computational Modeling of Cyclic Mobility and Post-Liquefaction Site Response. Soil Dyn. Earthquake Engrg., 22(4), 259-271.

Ghayoomi, M., Dashti, S., \& McCartney, J. S. (2013). Performance of a transparent Flexible Shear Beam container for geotechnical centrifuge modeling of dynamic problems. Soil 
Dynamics and Earthquake Engineering, 53(0), 230-239. doi: http://dx.doi.org/10.1016/j.soildyn.2013.07.007

Hashash, Y. M. A., Groholski, D., Musgrove, M., Park, D., Phillips, C., \& Tsai, C.-C. (2011). DEEPSOIL V5.0, Manual and Tutorial. Urbana, IL: Board of Trustees of University of Illinois at Urbana-Champaign.

Hashash, Y. M. A., Phillips, C., \& Groholski, D. R. (2010). Recent advances in nonlinear site response analysis. Paper presented at the Fifth International Conference in Recent Advances in Geotechnical Eartqhuake Engineering and Soil Dynamics, San Diego, CA.

Kramer, S. L. (1996). Geotechnical earthquake engineering. Upper Saddle River, N.J.: Prentice Hall.

Lambe, T. W. (1973). Predictions in soil engineering. Geotechnique, 23(2), 149-202.

Matasovic, N., \& Hashash, Y. (2012). NCHRP Synthesis 428: Practices and Procedures for Site-Specific Evaluations of Earthquake Ground Motions. Washington, D.C.

Mazzoni, S., McKenna, F., Scott, M., \& Fenves, G. (2006). Open System for earthquake engineering simulation user command-language. Berkeley, CA: NEES.

Mesri, G., \& Hayat, T. M. (1993). The coefficient of earth pressure at rest. Canadian Geotechnical Journal, 30, 647-666.

Mroz, Z. (1967). On the description of anisotropic work hardening. Jour. Mech. Phys. Solids, 15, 163-175.

Park, D., \& Hashash, Y. M. A. (2004). Soil damping formulation in nonlinear time domain site response analysis. Journal of Earthquake Engineering, 8(2), 249-274. 
Parra, E. (1996). Numerical modeling of liquefaction and lateral ground deformation including cyclic mobility and dilation response in soil system. Ph.D. Thesis, Rensselaer Polytechnic Institute, Troy, NY.

Phillips, C., \& Hashash, Y. M. A. (2009). Damping formulation for non-linear 1D site response analyses. Soil Dynamics and Earthquake Engineering, 29(7), Pages 1143-1158.

Phillips, C., Hashash, Y. M. A., Olson, S. M., \& Muszynski, M. R. (2012). Significance of small strain damping and dilation parameters in numerical modeling of free-field lateral spreading centrifuge tests. Soil Dynamics and Earthquake Engineering, 42(0), 161-176. doi: 10.1016/j.soildyn.2012.06.001

Prevost, J. H. (1985). A simple plasticity theory for frictional cohesionless soils. Soil Dynamics and Earthquake Engineering, 4(1), 9-17.

Rayleigh, J. W. S., \& Lindsay, R. B. (1945). The theory of sound (1st American ed.). New York: Dover Publications.

Seed, H. B., \& Idriss, I. M. (1970). Soil moduli and damping factors for dynamic response analyses. Berkeley: College of Engineering University of California Berkeley.

Terzaghi, K., \& Peck, R. B. (1948). Soil mechanics in engineering practice. New York: John Wiley \& Sons.

Terzaghi, K., Peck, R. B., \& Mesri, G. (1996). Soil Mechanics in Engineering Practice (Third Edition ed.). New York: Wiley.

VDC. (2014). Strong-Motion Virtual Data Center http://strongmotioncenter.org/vdc/scripts/search.plx 
Yang, Z. (2000). Numerical Modeling of Earthquake Site Response Including Dilation and Liquefaction. Ph.D. Thesis, Columbia University, NY, New York.

Yang, Z., Lu, J. and Elgamal, A. (2010). OpenSees manual for PDMY and PIMY materials <http://cyclic.ucsd.edu/opensees/>

Zeghal, M., Elgamal, A.-W., Tang, H. T., \& Stepp, J. C. (1995). Lotung downhole array II: evaluation of soil nonlinear properties. Journal of geotechnical engineering, 124(4), 363-377. 
Table 1: Summary of measured and estimated Nevada Sand properties used in the numerical analyses.

\begin{tabular}{|c|c|c|}
\hline Variable & Value & Unit \\
\hline Assumed Specific Gravity, $\mathrm{G}_{\mathrm{s}}$ & 2.65 & --- \\
\hline Maximum Dry Unit Weight, $\gamma_{\mathrm{d}, \mathrm{max}} *$ & 16.39 & $\mathrm{kN} / \mathrm{m}^{3}$ \\
\hline Minimum Dry Unit Weight, $\gamma_{\mathrm{d}, \min } *$ & 14 & $\mathrm{kN} / \mathrm{m}^{3}$ \\
\hline Minimum Void Ratio, $\mathrm{e}_{\min }{ }^{*}$ & 0.586 & --- \\
\hline Maximum Void Ratio, $\mathrm{e}_{\max } *$ & 0.852 & --- \\
\hline Relative density, $\mathrm{D}_{\mathrm{r}}{ }^{*}$ & 60 & $\%$ \\
\hline Dry unit weight, $\gamma_{\mathrm{d}}$ & 15.34 & $\mathrm{kN} / \mathrm{m}^{3}$ \\
\hline Dry density, $\rho_{\mathrm{d}}$ & 1.56 & $\mathrm{Mg} / \mathrm{m}^{3}$ \\
\hline Void ratio, $\mathrm{e}$ & 0.692 & --- \\
\hline Estimated friction angle, $\phi$ & 33 & --- \\
\hline Coefficient of earth pressure at rest, $\mathrm{K}_{\mathrm{o}}$ & 0.46 & --- \\
\hline $\mathrm{K}_{2, \text { max }}$ (Seed and Idriss, 1970$)$ & 48 & --- \\
\hline
\end{tabular}

(*) Measured Properties. 
Table 2: Input Ground Motion Characteristics.

\begin{tabular}{|c|c|c|c|c|c|c|c|c|c|}
\hline \multicolumn{4}{|c|}{ Source Motion } & \multicolumn{3}{c|}{ Achieved Parameters } \\
\hline Event & Year & $\mathrm{M}_{\mathrm{w}}$ & $\begin{array}{c}\text { Station } \\
\text { Name }\end{array}$ & $\begin{array}{c}\text { Recording } \\
\text { Identifier }\end{array}$ & $\begin{array}{c}\text { Distance } \\
\text { to rupture } \\
(\mathrm{km})\end{array}$ & $\begin{array}{c}\text { PGA } \\
(\mathrm{g})\end{array}$ & $\begin{array}{c}\mathrm{T}_{\mathrm{p}} \\
(\mathrm{s})\end{array}$ & $\begin{array}{c}\text { AI } \\
(\mathrm{m} / \mathrm{s})\end{array}$ & $\begin{array}{c}\mathrm{D}_{5-95} \\
(\mathrm{~s})\end{array}$ \\
\hline Landers & 1992 & 7.3 & $\begin{array}{c}\text { Joshua } \\
\text { Tree }\end{array}$ & JOS090 & 10 & 0.33 & 0.64 & 2.78 & 27 \\
\hline $\begin{array}{c}\text { Loma } \\
\text { Prieta }\end{array}$ & 1989 & 7 & $\begin{array}{c}\text { Santa } \\
\text { Cruz Lick } \\
\text { Observ. }\end{array}$ & SCZ090 & 18.8 & 0.33 & 0.16 & 2.12 & 11.34 \\
\hline Northridge & 1994 & 6.7 & $\begin{array}{c}\text { Newhall } \\
\text { W Pico } \\
\text { Canyon }\end{array}$ & WPI046 & 9.4 & 0.6 & 0.4 & 1.98 & 13.88 \\
\hline Chi-Chi & 1999 & 7.6 & TCU078 & TCU078 & 8.3 & 0.47 & 0.34 & 6.03 & 28.76 \\
\hline Landers & 1992 & 7.3 & Lucerne & LCN260 & 2 & 0.55 & 0.28 & 7.06 & 14.12 \\
\hline Kobe & 1995 & 6.9 & Takatori & TAK090 & 1.5 & 0.76 & 0.4 & 9.16 & 25.78 \\
\hline
\end{tabular}

* $\mathrm{M}_{\mathrm{w}}$ : Moment magnitude

Moment magnitude and distance to rupture as reported in Strong-Motion Virtual Data Center (VDC 2014) 
Table 3: Offset on LVDT 6 after each motion.

\begin{tabular}{|c|c|}
\cline { 2 - 2 } \multicolumn{1}{c|}{} & Offset $(\mathrm{m})$ \\
\hline NorthridgeWPI & 0.026 \\
\hline KobeTAK & -0.032 \\
\hline LandersJOS & -0.029 \\
\hline LandersLCN & -0.026 \\
\hline LomaSCZ & 0.006 \\
\hline ChiTCU & 0.003 \\
\hline
\end{tabular}

Page: 30 of 45 
Table 4: Assumed parameters for Darendeli's (2001) modulus reduction and damping curves.

\begin{tabular}{|c|c|}
\hline Parameters & Assumed values \\
\hline $\mathrm{K}_{\mathrm{o}}$ & 0.46 \\
\hline $\mathrm{PI}(\%)$ & 0 \\
\hline $\mathrm{OCR}$ & 1 \\
\hline $\mathrm{N}$ & 10 \\
\hline Freq.(Hz) & 1 \\
\hline
\end{tabular}

Page: 31 of 45 
Table 5: Assumed parameters for Pressure Dependent model (Elgamal 2002; Yang 2000) used in the Class C prediction for dry Nevada Sand $\left(D_{r}=60 \%\right)$.

\begin{tabular}{|c|c|c|}
\hline Variable & Value & Units \\
\hline Mass density & 1.56 & $\mathrm{Mg} / \mathrm{m}^{3}$ \\
\hline Ref. shear modulus, $G_{r}$ & $8.29 \mathrm{e} 4$ & $\mathrm{kN} / \mathrm{m}^{2}$ \\
\hline Ref. mean confinement, $p_{r}^{\prime}$ & 80 & $\mathrm{kN} / \mathrm{m}^{2}$ \\
\hline Poisson's ratio & 0.31 & --- \\
\hline Ref. bulk modulus, $B_{\mathrm{r}}$ & $1.91 \mathrm{e} 5$ & $\mathrm{kN} / \mathrm{m}^{2}$ \\
\hline Confinement dependence coefficient, $d$ & 0.5 & --- \\
\hline Friction angle, $\phi$ & 33 & $\circ$ \\
\hline Peak shear strain, $\gamma_{\max }$ & 10 & $\%$ \\
\hline Number of Yield surfaces & 20 & --- \\
\hline Phase transformation angle & 26.5 & $\circ$ \\
\hline Initial void ratio & 0.692 & --- \\
\hline Contraction parameter & 0.05 & --- \\
\hline Dilation parameters & $\mathrm{d}_{1}=0.6 / \mathrm{d}_{2}=2$ & --- \\
\hline Liquefaction induced strain constants & 0 & --- \\
\hline
\end{tabular}




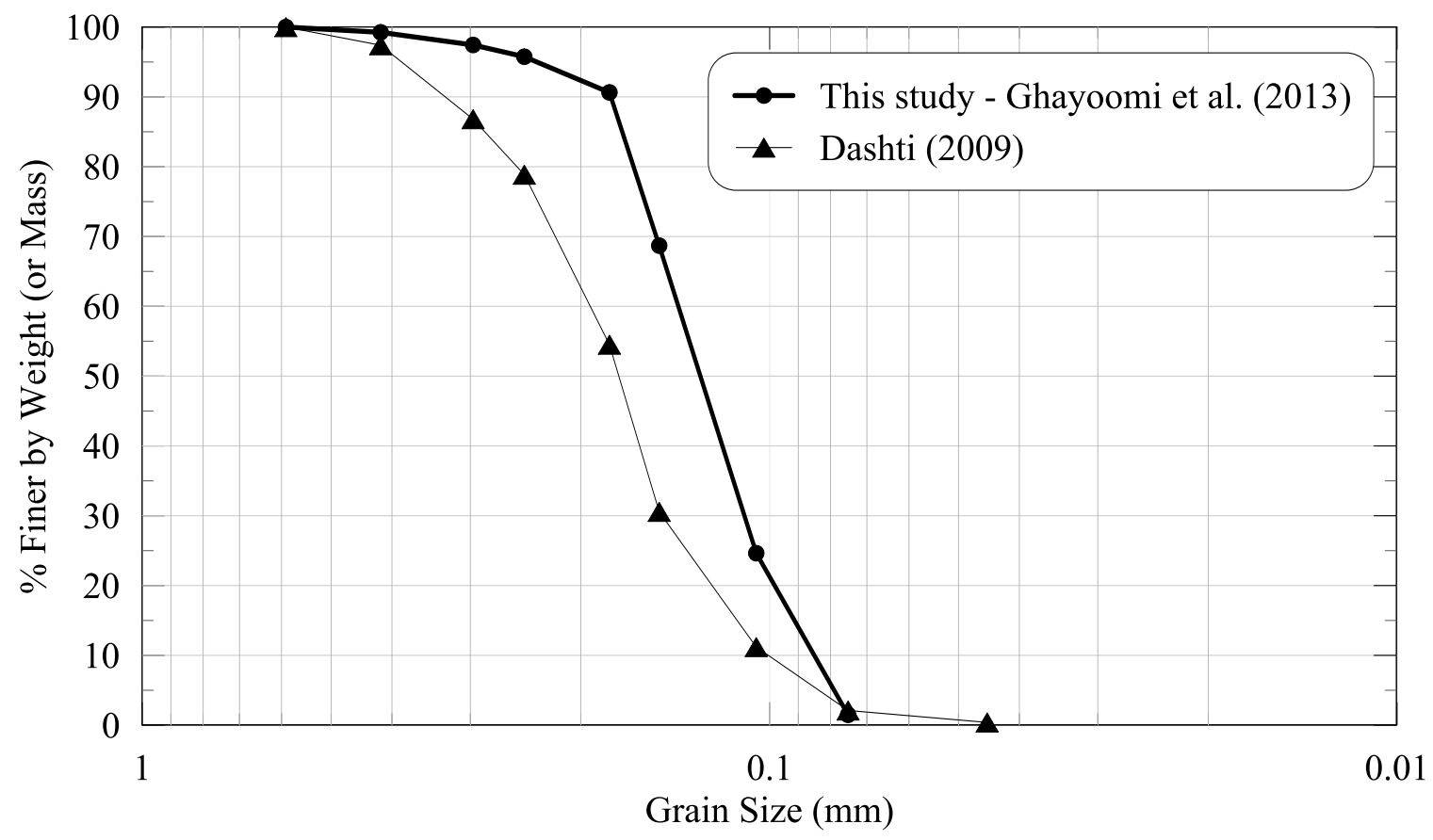

Figure 1: Nevada Sand gradation curve used in this study $(\mathrm{Cu}=1.62$ and $\mathrm{Cc}=1.004)$ compared to one prior study. 


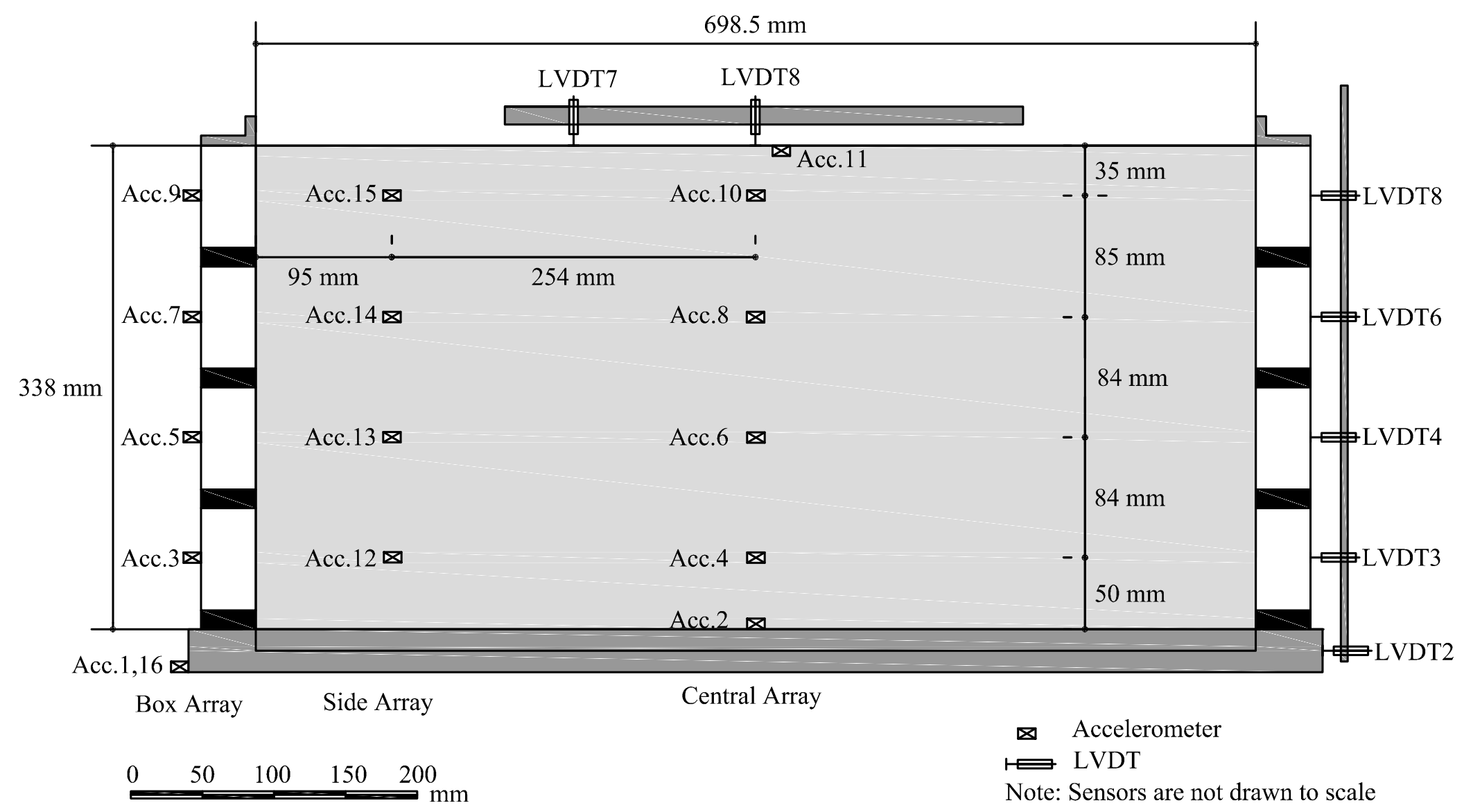

Figure 2: Schematic of centrifuge experiment instrumentation layout

(Dimensions shown in model scale). 

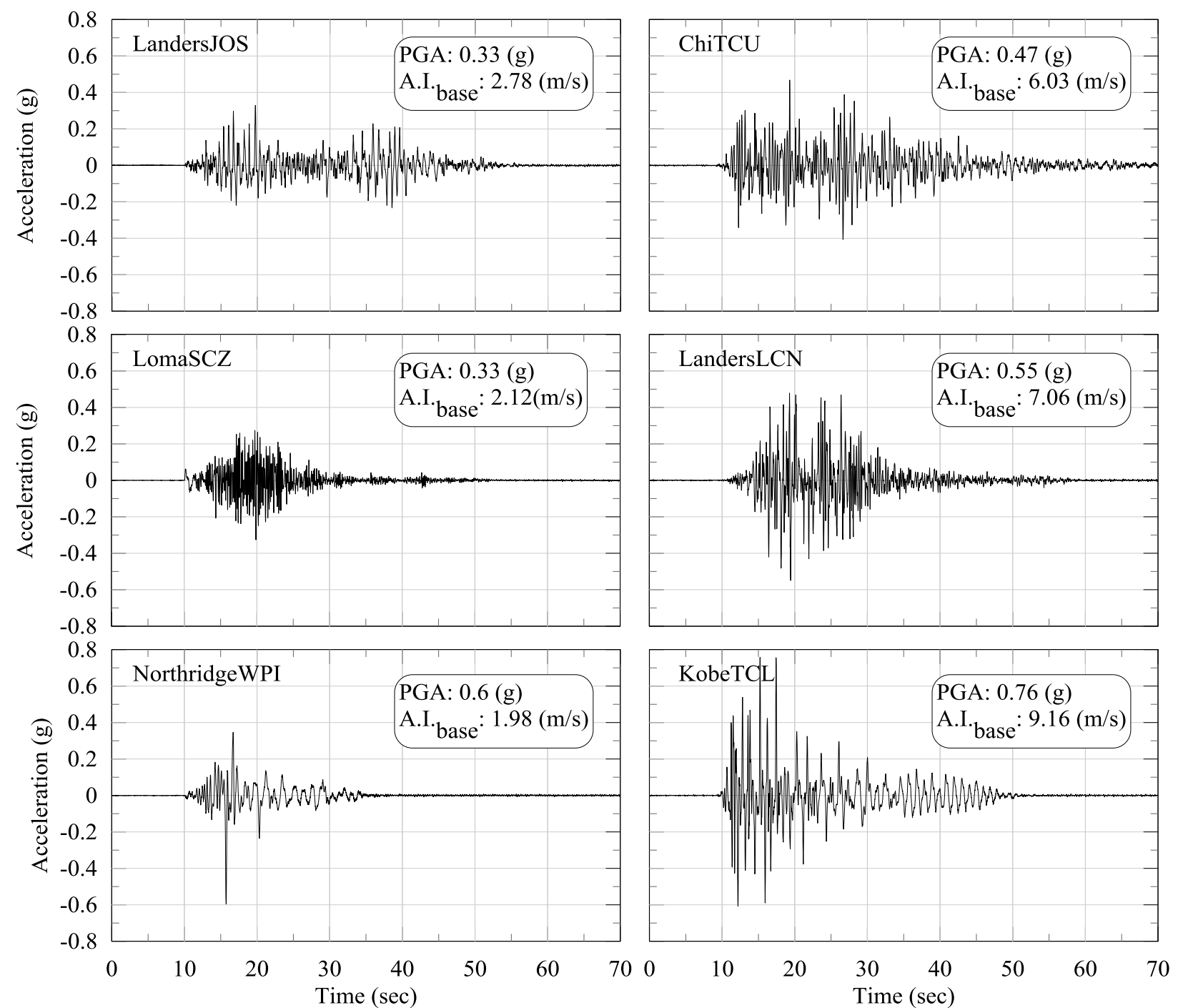

Figure 3: Container base motions as recorded and input into the analyses. 


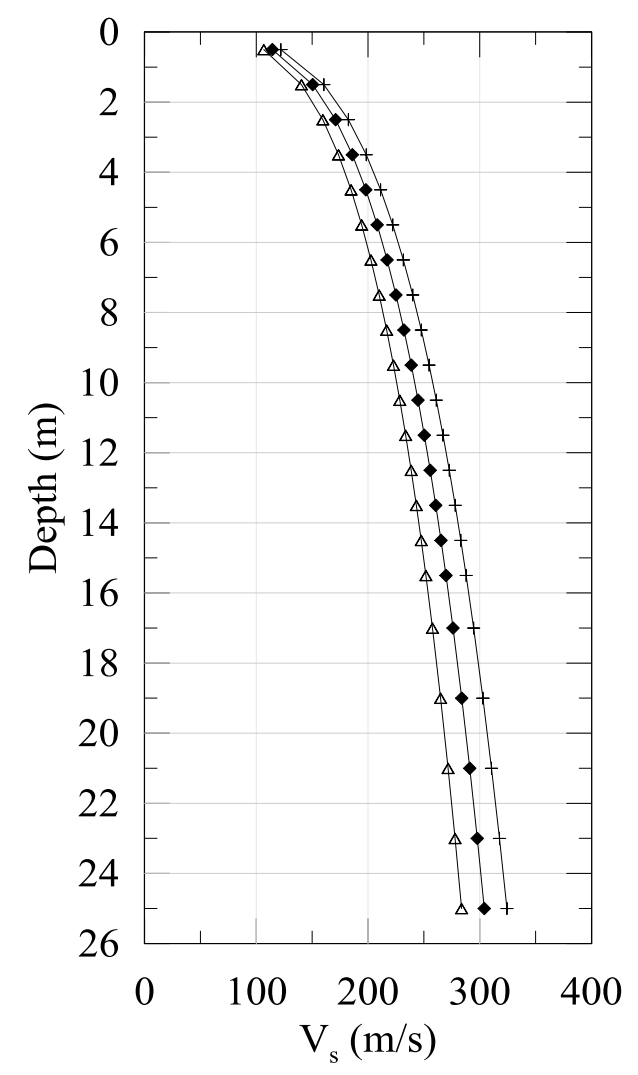

$$
\begin{aligned}
& + \text { Seed and Iddriss (1970) } \\
& - \text { Bardet et. al (1993) } \\
& -\mathrm{V}_{\mathrm{s} \text { average }} \text { (used in analyses) }
\end{aligned}
$$

Figure 4: $\mathrm{V}_{\mathrm{s}}$ profile used in site response analyses. 


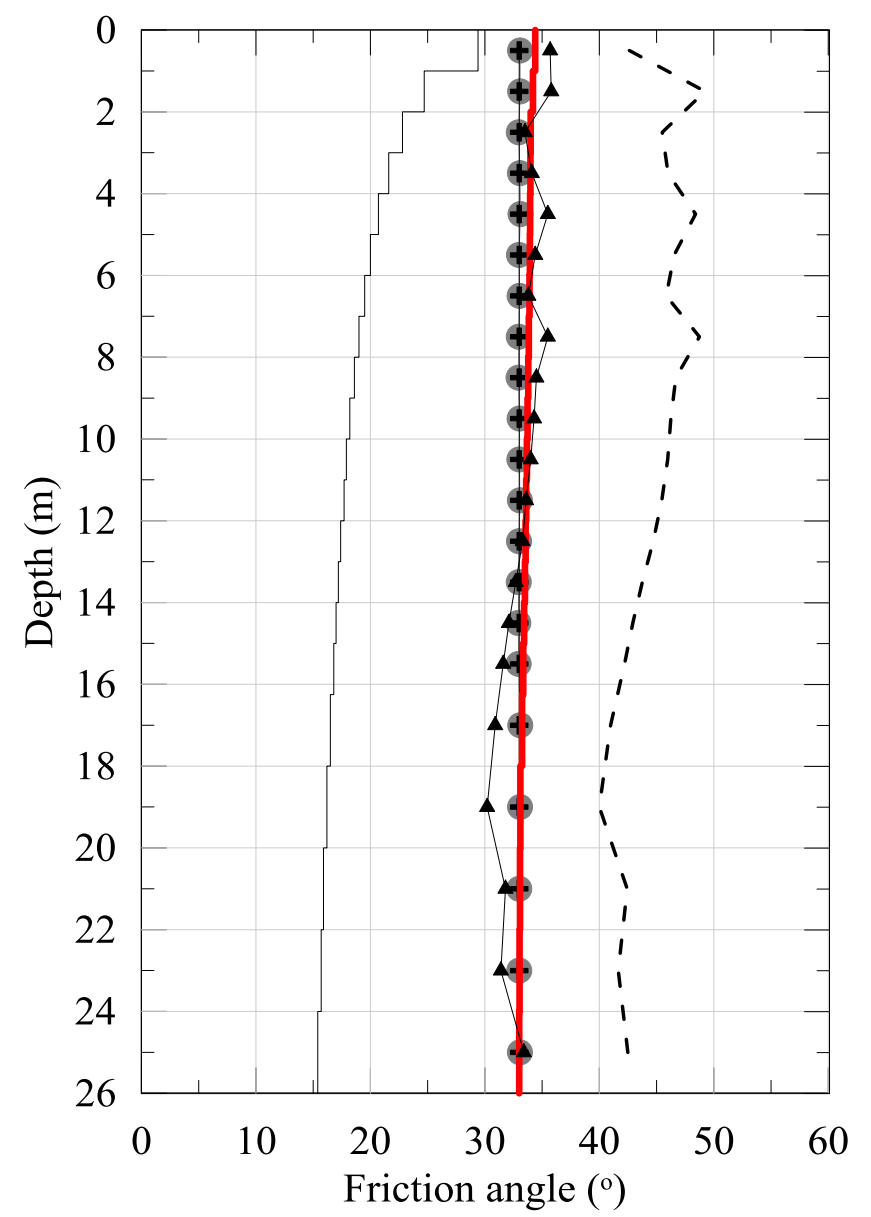

Darendeli's implied friction angle at large strains

- Target friction angle

— Deepsoil - Class C - Darendeli's final fit

+ OpenSees - Class C

- - - OpenSees - Class C1 before MR curve modification

- OpenSees - Class C1

Figure 5: Implied friction angle profile used in Class $\mathrm{C}$ and Class $\mathrm{C} 1$ analyses. 

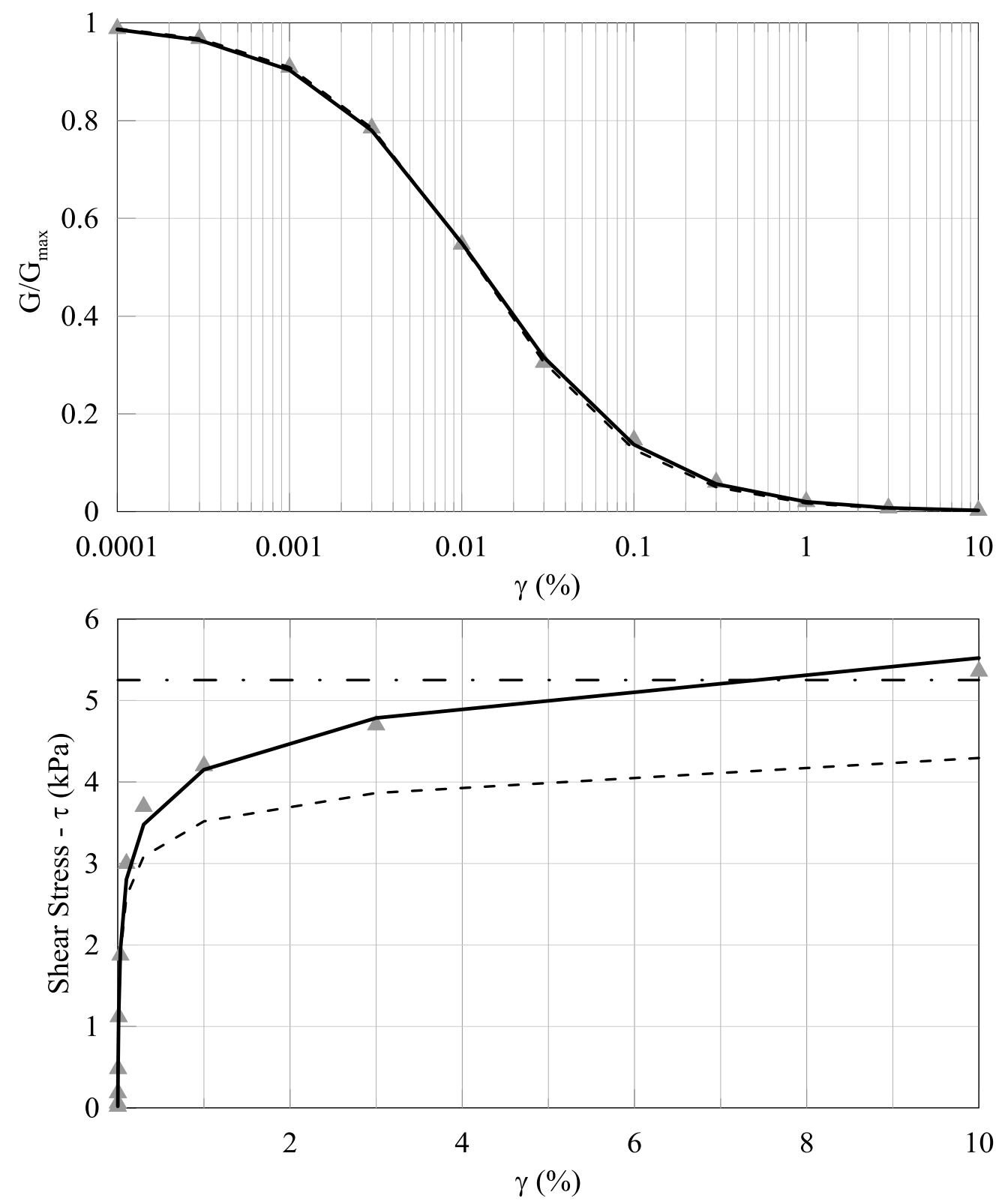

- - - Original Darendeli's MRDF Implied Shear Strength

- . Target shear strength at large strains

- Manual Fit

— Darendeli's Final Fit - Deepsoil Class C

Figure 6: Implied shear strength correction procedure for the superficial layer. 

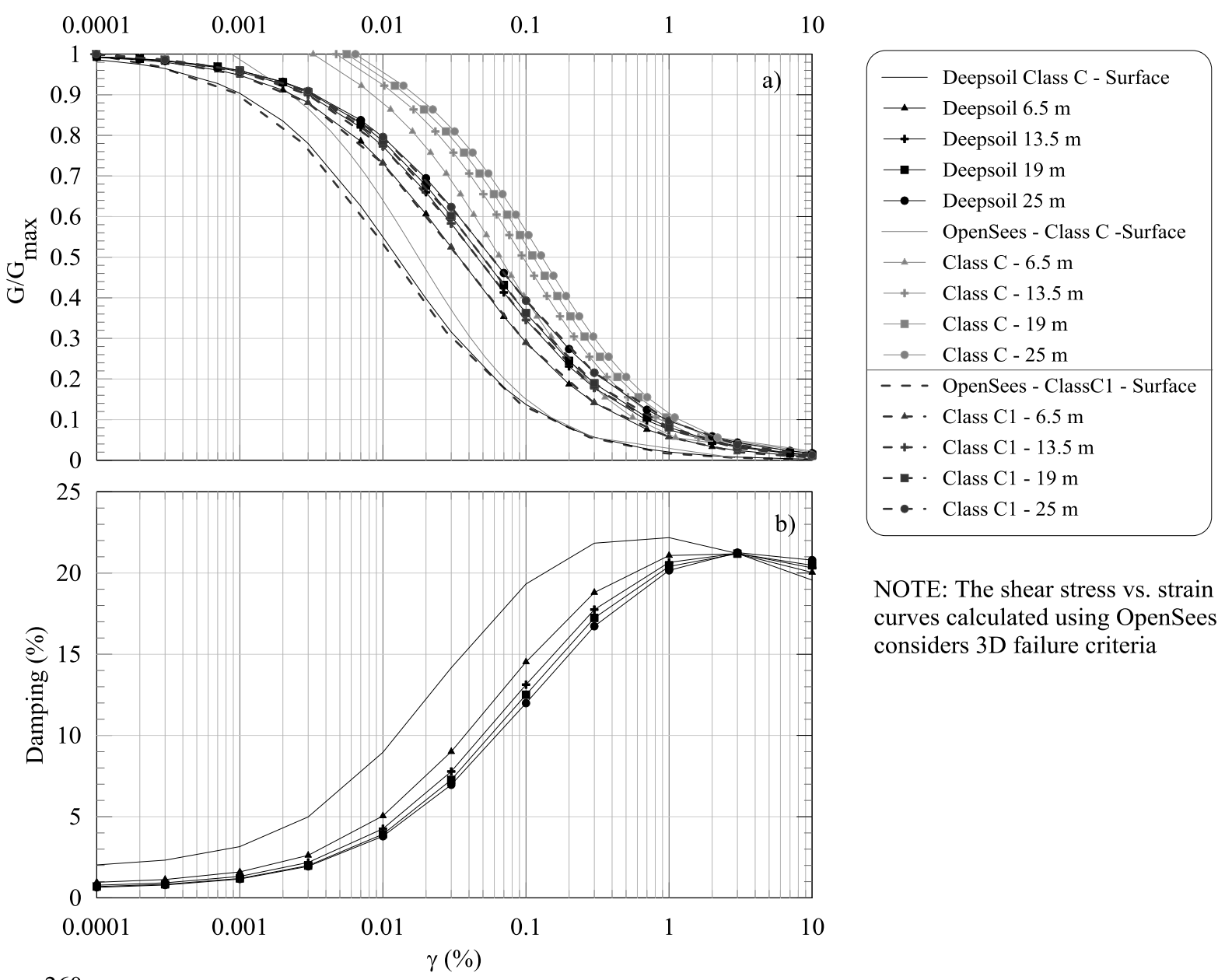

NOTE: The shear stress vs. strain curves calculated using OpenSees considers $3 \mathrm{D}$ failure criteria

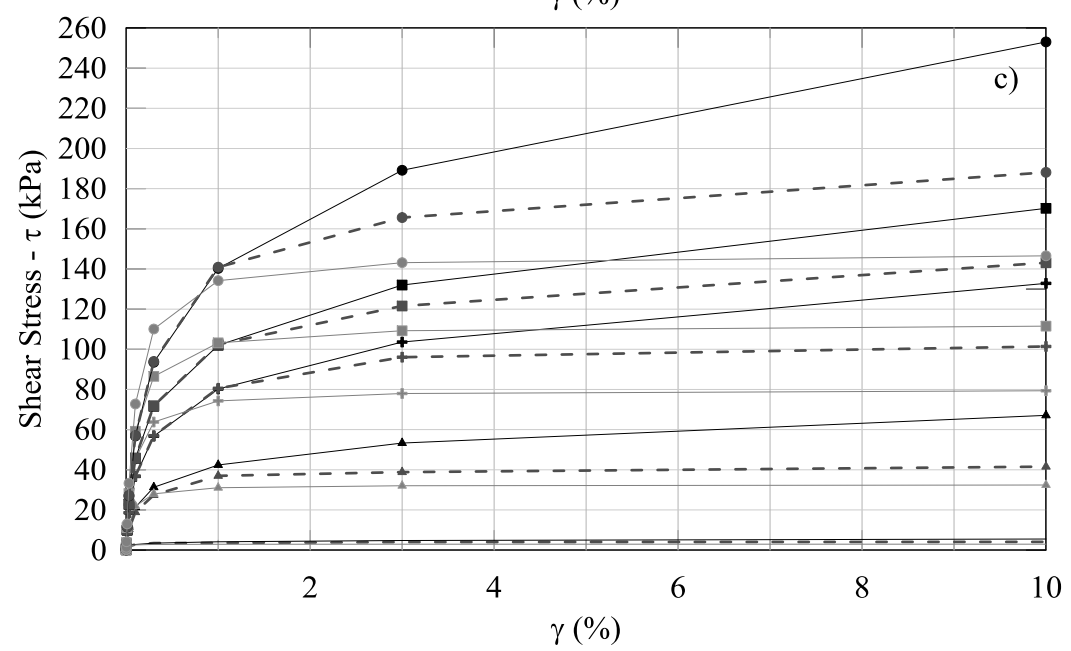

Figure 7: Modulus reduction, damping, and strain-stress curves used in the numerical analyses. 

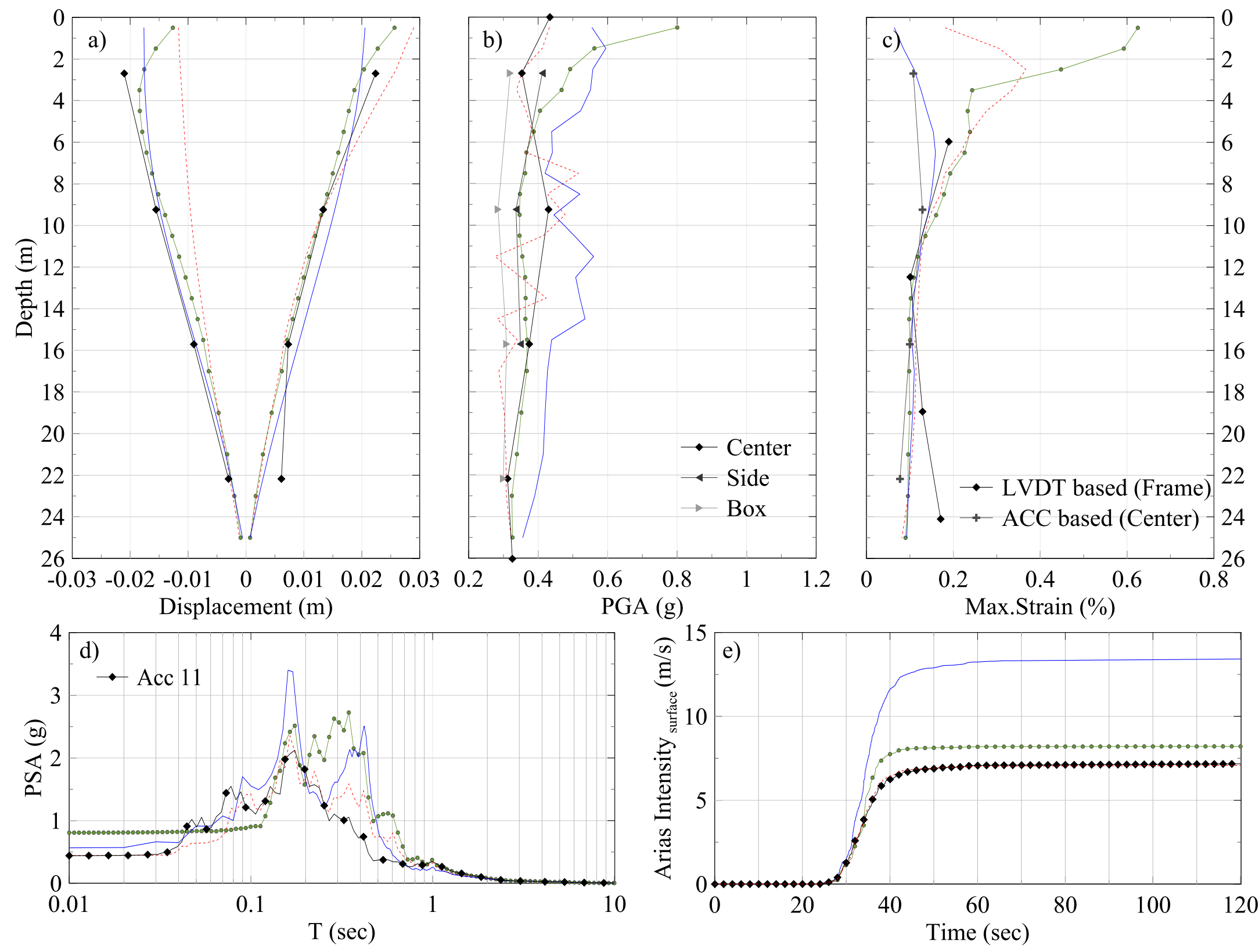

- LomaSCZ - Deepsoil Eq.Linear …-.. LomaSCZ - Deepsoil Nonlinear — LomaSCZ - OpenSees $\rightarrow$ Centrifuge

Figure 8: Comparison between Class $\mathrm{C}$ predictions and centrifuge measurements during the LomaSCZ motion.

Page: 40 of 45 

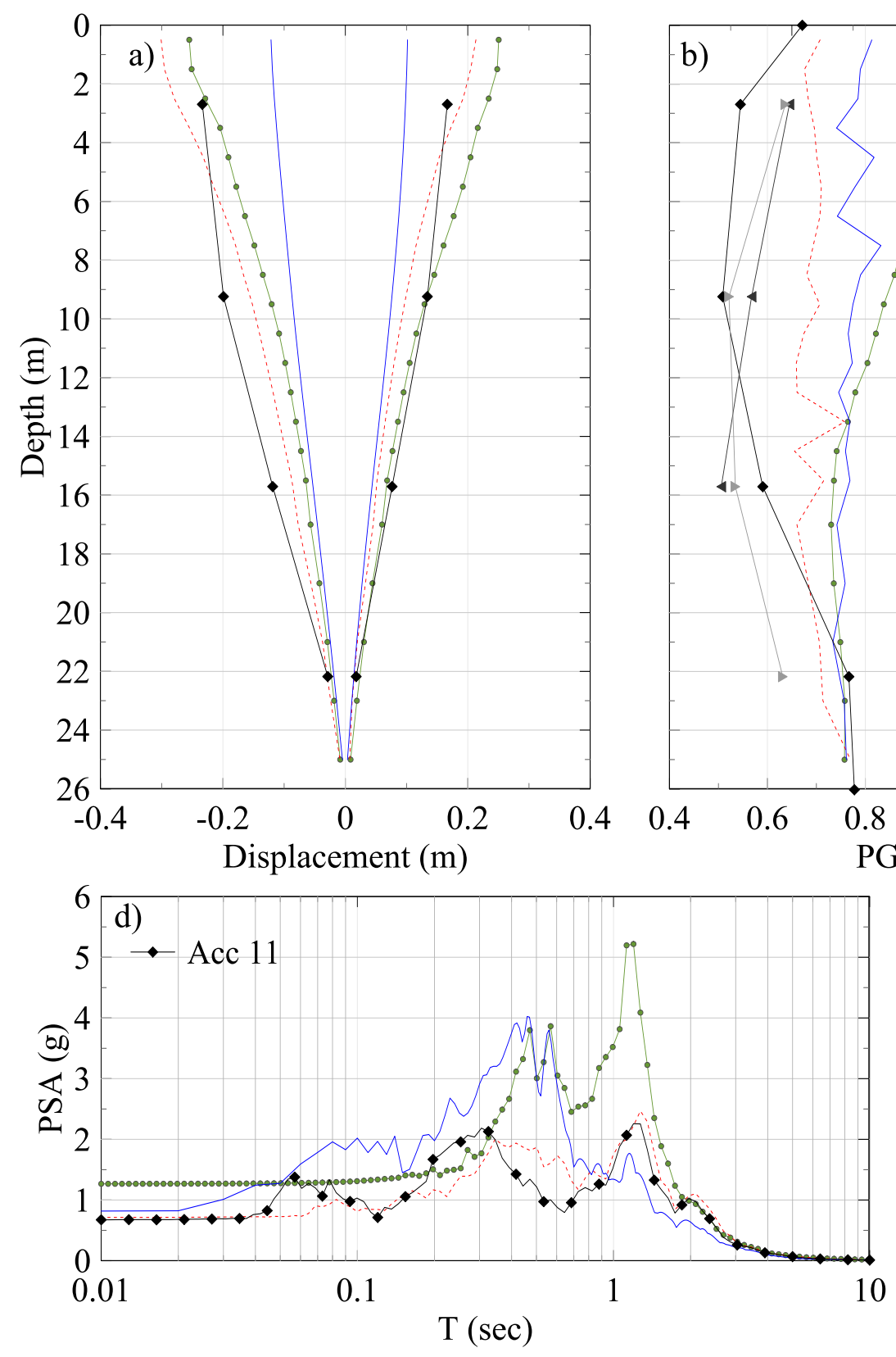
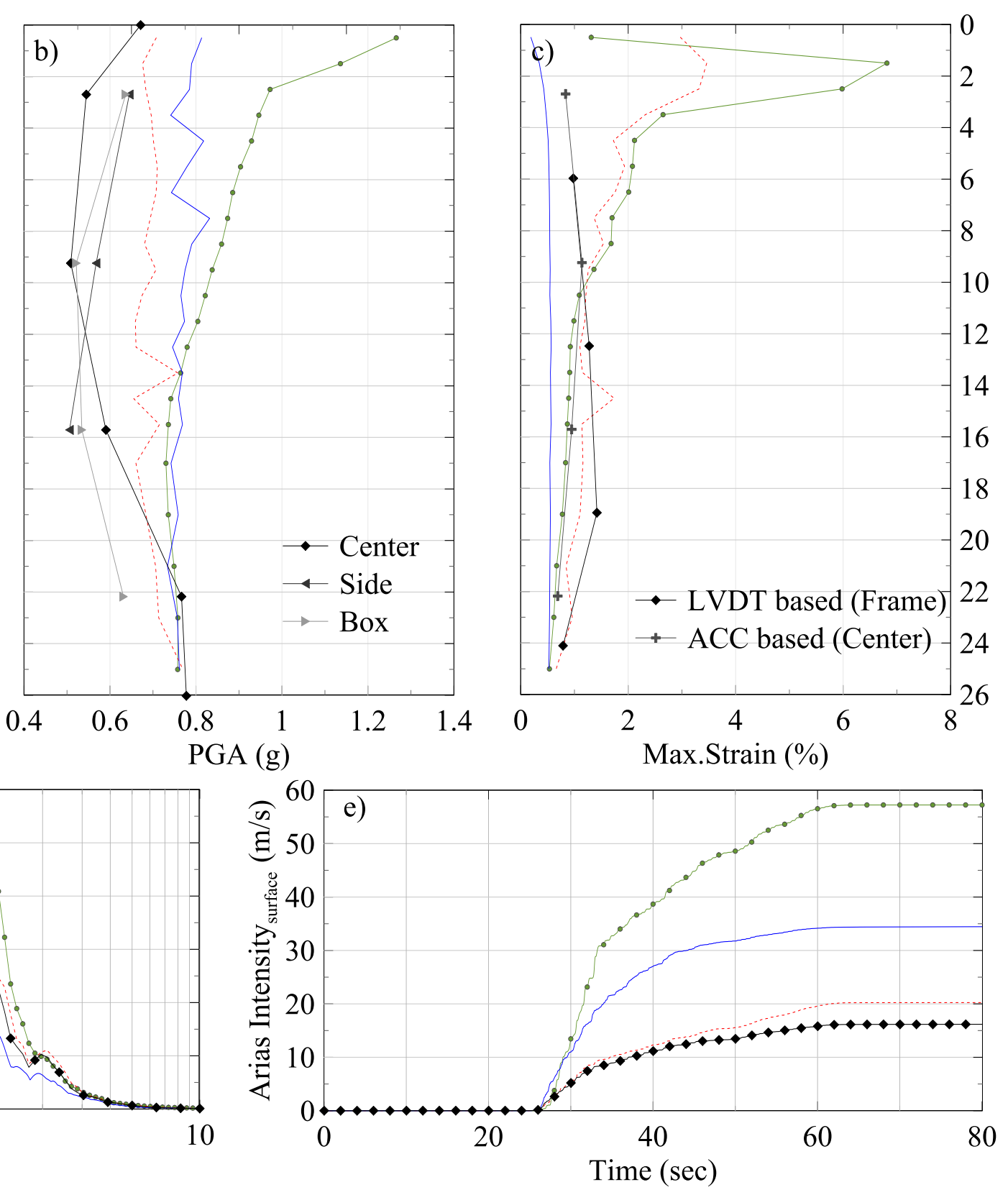

\section{KobeTAK - Deepsoil Eq.Linear \\ KobeTAK- Deepsoil Nonlinear \\ Kobe TAK - OpenSees \\ Centrifuge}

Figure 9: Comparison between Class C predictions and centrifuge measurements during the KobeTAK motion.

Page: 41 of 45 

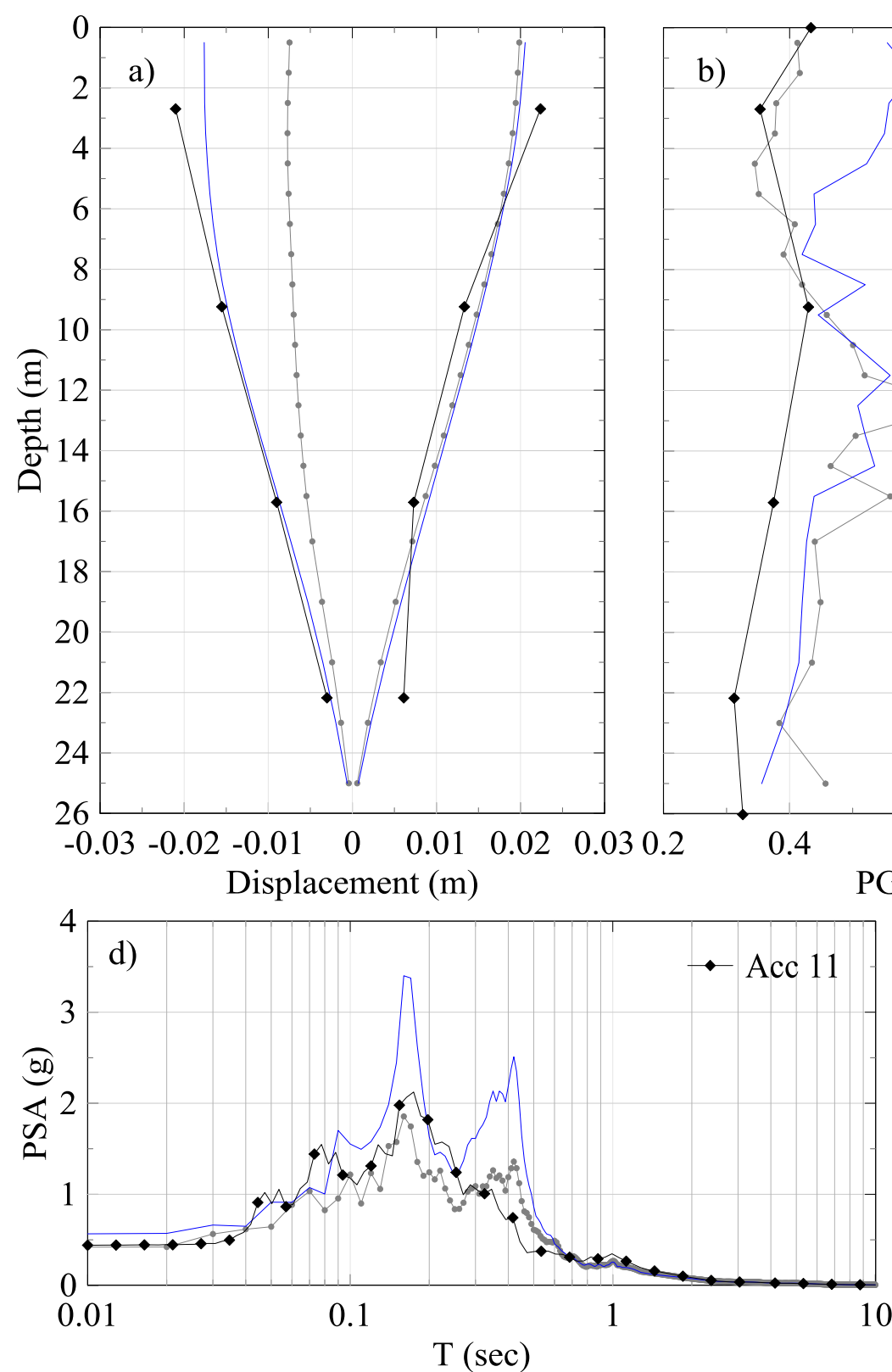
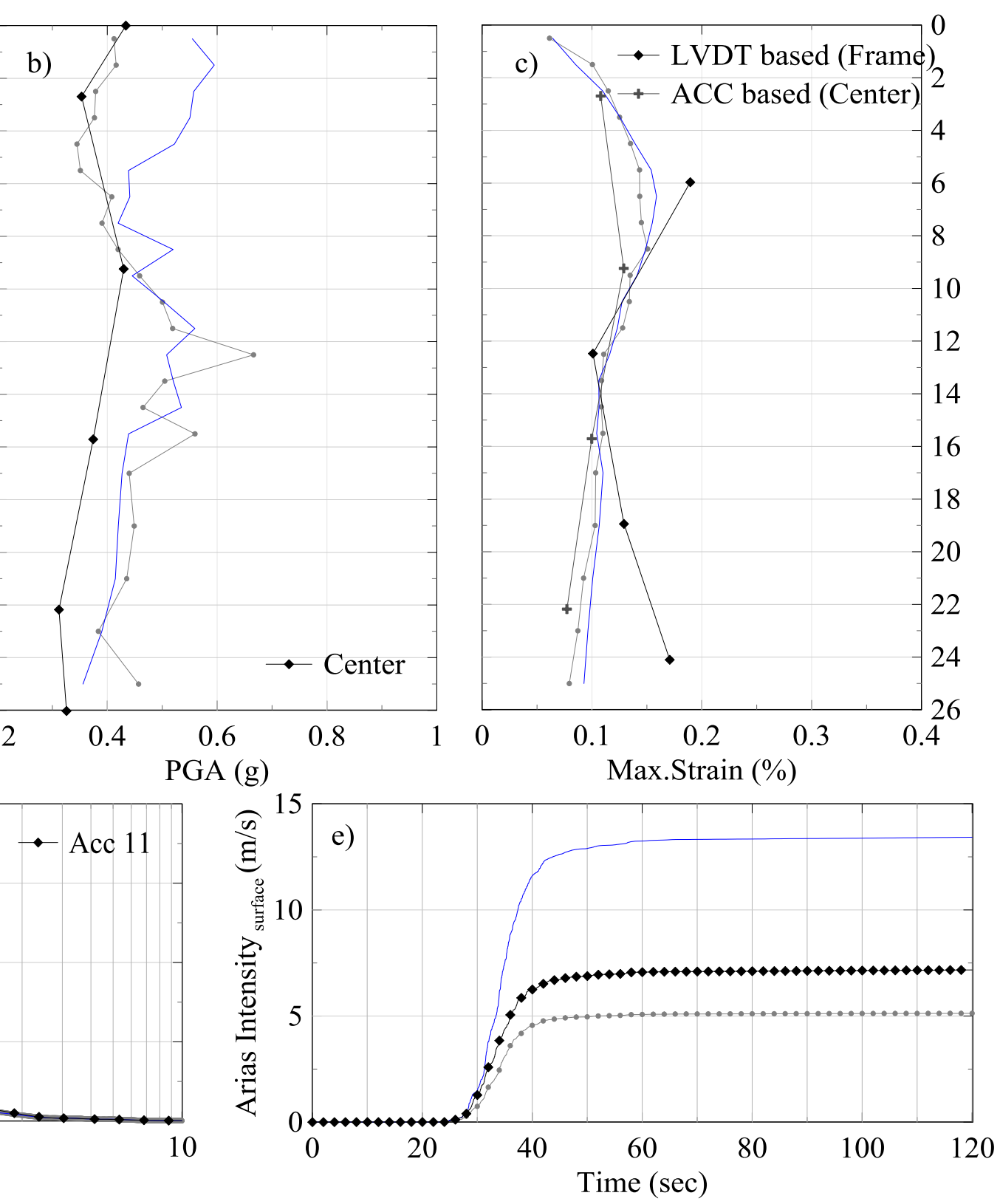

- LomaSCZ - OpenSees - Class C1 - LomaSCZ - OpenSees - Class C $\rightarrow$ Centrifuge

Figure 10: Comparison between Class C1, Class C OpenSees predictions and centrifuge measurements - Loma SCZ.

Page: 42 of 45 

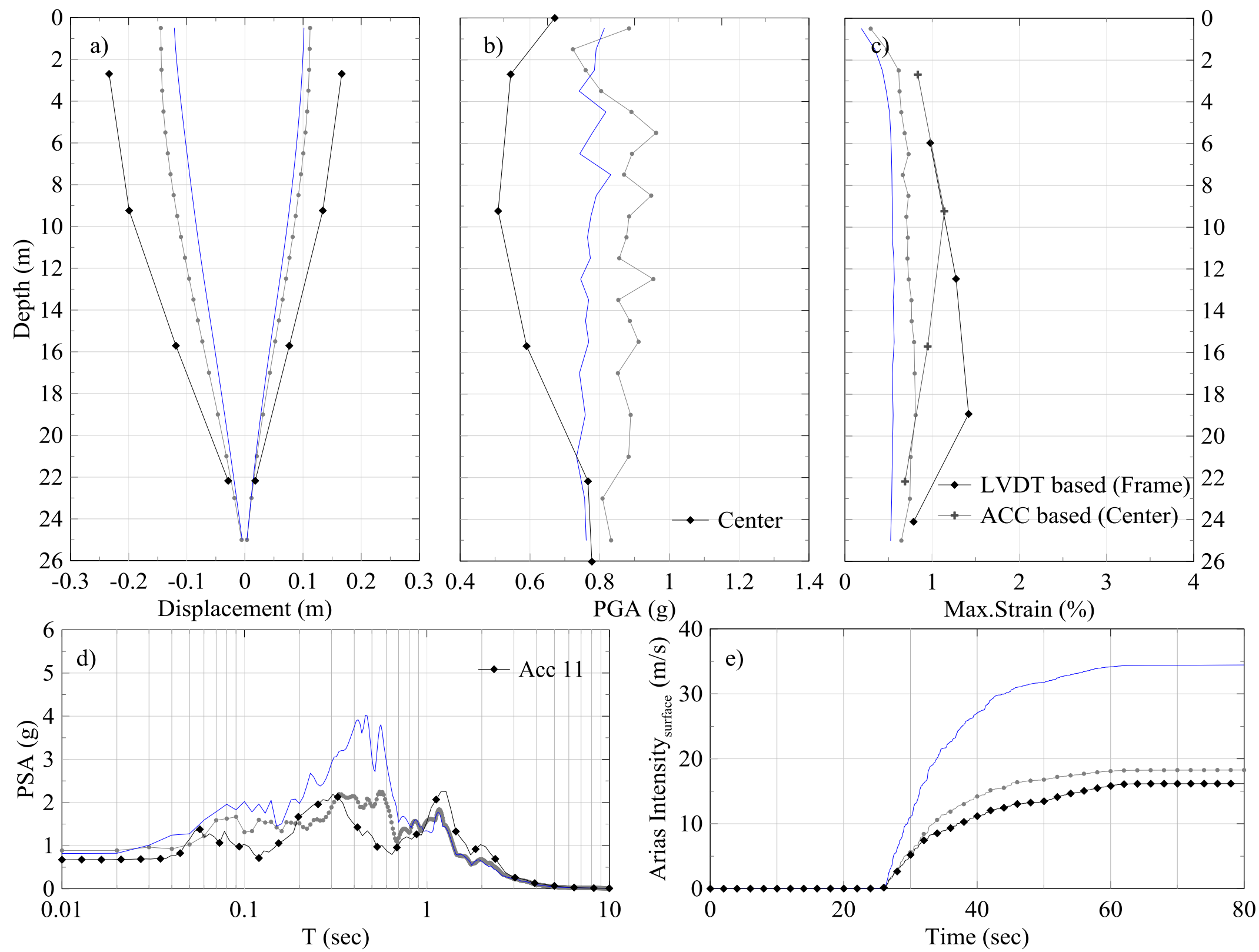

- KobeTAK - OpenSees - Class C1 Kobe TAK - OpenSees - Class C $\rightarrow$ Centrifuge

Figure 11: Comparison between Class C1, Class C OpenSees predictions and centrifuge measurements - Kobe TAK.

Page: 43 of 45 

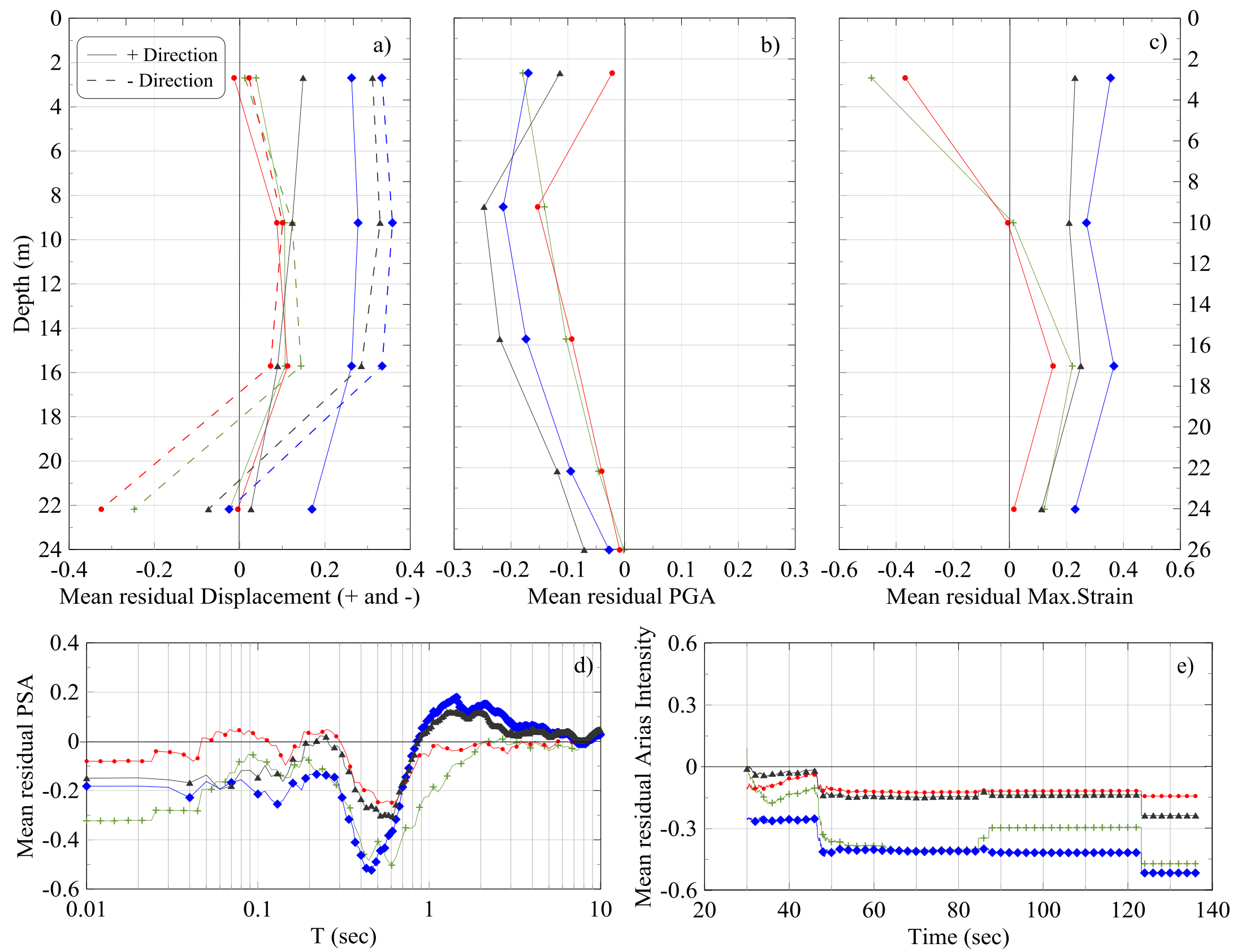

- Deepsoil Nonlinear + Deepsoil Eq.Linear - OpenSees Class C $\leftarrow$ OpenSees Class C1

Figure 12: Comparison of mean residuals for different analysis methods and response parameters.

Page: 44 of 45 

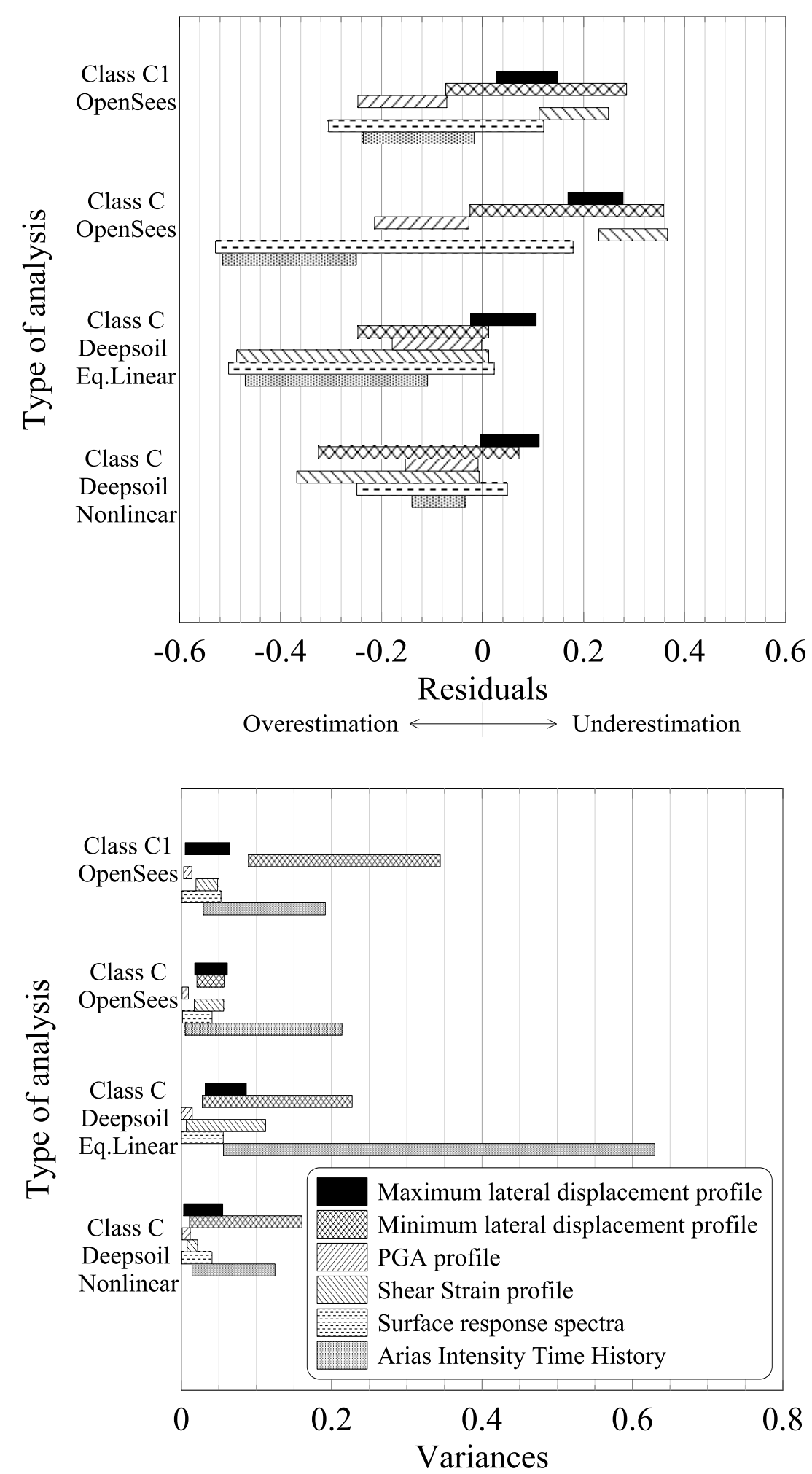

Figure 13: Range of mean residuals and variances obtained for each analysis type and response parameter. 